\title{
Vertical patterns of photosynthesis and related leaf traits in two contrasting agricultural crops
}

\section{Journal Article}

Author(s):

D'Odorico, Petra; Emmel, Carmen (i); Revill, Andrew; Liebisch, Frank; Eugster, Werner (D); Buchmann, Nina (D)

Publication date:

2019

Permanent link:

https://doi.org/10.3929/ethz-b-000300097

Rights / license:

In Copyright - Non-Commercial Use Permitted

Originally published in:

Functional Plant Biology 46(3), https://doi.org/10.1071/FP18061

Funding acknowledgement:

146373 - The role of diffuse radiation for a long-term arable crop rotation at Oensingen, Switzerland (Acronym: DiRad Oensingen) (SNF) 


\title{
Vertical patterns of photosynthesis and related leaf traits in two contrasting agricultural crops
}

\author{
Petra D’Odorico, ${ }^{\mathrm{a}, \mathrm{b},}$, Carmen Emmel ${ }^{\mathrm{a}}$, Andrew Revill ${ }^{\mathrm{a}, \mathrm{c}}$, Frank Liebisch ${ }^{\mathrm{a}}$, Werner Eugster ${ }^{\mathrm{a}}$ \\ and Nina Buchmann ${ }^{\mathrm{a}}$ \\ * Corresponding author: Petra D’Odorico, petra.dodorico@usys.ethz.ch \\ ${ }^{a}$ Institute of Agricultural Sciences, Swiss Federal Institute of Technology Zurich, 8092 Zurich, Switzerland. \\ ${ }^{b}$ now at Department of Biology, University of Toronto Mississauga, L5L1C6 Mississauga, Canada. \\ ${ }^{\mathrm{c}}$ now at School of Geosciences, University of Edinburgh, EH8 9XP Edinburgh, Scotland.
}

\begin{abstract}
To include within-canopy leaf acclimation responses to light and other resource gradients in photosynthesis modelling, it is imperative to understand the variation of leaf structural, biochemical and physiological traits from canopy top to bottom. In this study, leaf photosynthetic traits for top and bottom canopy leaves, canopy structure and light profiles, were measured over one growing season for two contrasting crop types, winter barley (Hordeum vulgare L.) and rape seed (Brassica napus L.). With the exception of quantum yield, other traits such as maximum photosynthetic capacity (Amax), dark respiration, leaf nitrogen and chlorophyll contents, and leaf mass per area, showed consistently higher $(p<0.05)$ values for top leaves throughout the growing season and for both crop types. Even though Amax is higher for top leaves, the bottom half of the canopy intercepts more light and thus contributes the most to total canopy photosynthesis up until senescence sets in. Incorporating this knowledge into a simple top/bottom-leaf upscaling scheme, separating top and bottom leaves, resulted in a better match between estimated and measured total canopy photosynthesis, compared to a one-leaf upscaling scheme. Moreover, aggregating to daily and weekly temporal resolutions progressively increased the linearity of the leaf photosynthetic responses to light for top leaves.
\end{abstract}

Keywords: photosynthesis; leaf trait; photosynthesis trait; upscaling; one-leaf model; top/bottom-leaf model; leaf area index; canopy nitrogen.

\section{Introduction}

Leaves within a canopy have access to analogous below-ground nutrients and water resources, while light conditions they experience vary greatly depending on their position within the canopy, particularly as a function of height. Among the factors affecting plant functioning, light is perhaps the most spatially (i.e., vertical gradient) and temporally heterogeneous, although closed canopies are typically characterized by a drop in light availability from canopy top to bottom (Pearcy 1999). Within-canopy light gradients, which define the past and current light exposure of a given leaf, trigger acclimation responses through variations in leaf structural, biochemical and physiological traits (Niinemets et al. 2015). The type of acclimation response is often optimized for the particular species. In slow leaf turnover species, mostly populating the northern forest ecosystems, the light regime at a specific height within the canopy is relatively constant after canopy closure and a passive photosynthesis acclimation response occurs mostly by changes of leaf structural traits to light (Niinemets et al. 2015; Coble et al. 2016). In contrast, fast leaf turnover species such as grasses and agricultural crops, are characterized by highly dynamic light environments within their canopies (Husse et al. 2016). In agricultural crops, every new leaf is born as a sun leaf and as leaves age they occupy successively more poorly lit positions within the plant canopy. The short phenological cycles, 
and shade acclimation times, in crop species make it unprofitable for the plants to invest in slow structural changes (Wright et al. 2004; Niinemets et al. 2015) and active changes of

Under low light conditions plants need to invest in proteins for building light capturing structures, e.g. chlorophyll a and b, while sunlit leaves invest less in light capturing and more in proteins involved in the assimilation of intercellular $\mathrm{CO}_{2}$, e.g. in RuBisCO (Evans and Poorter 2001). As both, the RuBisCO and the electron transport limited rate of carboxylation, are expensive in terms of $\mathrm{N}$, there is potentially a trade-off in the investment in structures that increase the capacity for light capture and carbon (C) assimilation (Chen et al. 1993; Niinemets 1998). Accordingly, the allocation of resources in light or C capturing structures will point to potential environmental constraints on photosynthesis at a specific leaf position. Commonly, $\mathrm{N}$ concentrations have repeatedly been shown to increase from bottom to top of canopy, where ample light is available for higher photosynthetic C fixation (De Pury and Farquhar 1997; Evans and Poorter 2001; Kattge et al. 2009; Coble and Cavaleri 2015). At the canopy level however, light availability and interception by leaves, and thus total canopy photosynthesis, ultimately depend on canopy architecture. Canopy architecture, mainly defined by leaf arrangement in space, known as foliage clumping index (Gonsamo and Pellikka 2009), leaf angle and area, can widely vary across crop species, resulting in different light interception for photosynthesis (Falster and Westoby 2003). Therefore, in order to include within-canopy leaf acclimation responses to light and other resource gradients in crop photosynthesis modelling, it is imperative to understand the variation of leaf structural, biochemical and physiological traits from canopy top to bottom (De Pury and Farquhar 1997).

Crop photosynthesis is a key driver in many crop models. Photosynthesis models for agricultural crops have evolved from simple statistical modeling of the photosynthetic light response (Blackman 1905) and its upscaling to canopy level (Monsi and Saeki 1953), to linking crop growth simulation models with light response functions (e.g., (De Wit 1978)). At the crop canopy scale, radiation use efficiency (RUE), representing crop growth stage in many crop models (Parent et al. 2015), has been successfully used to simulate the total photosynthesis of a given canopy avoiding the need for photosynthesis upscaling (Monteith JL and Moss 1977; Sinclair and Muchow 1999). The RUE concept first introduced by Monteith (1972) states that net $\mathrm{C}$ gain is a function of the amount of absorbed photosynthetically active radiation (APAR) and the RUE with which vegetation converts the APAR into biomass. The simple empirical linear relationship based on RUE however lacks proper representation of structural, biochemical and physiological processes required to capture canopy photosynthesis responses to vertical resource gradients and environmental cues.

On the other hand, mechanistic models of photosynthesis, based on key biochemical processes of photosynthesis, have been developed at the leaf level (Farquhar et al. 1980; von Caemmerer and Farquhar 1981; Farquhar and von Caemmerer 1982; von Caemmerer 2000) and up-scaled to the canopy level following various schemes (Norman and Jarvis 1974; Norman and Welles 1983; Sellers et al. 1992; Leuning 1995; De Pury and Farquhar 1997). The two most commonly used upscaling schemes are, the big-leaf approach, which treats a canopy as a big-leaf (Sellers et al. 1992; Sands 1995), and the sun/shade leaf approach, which partitions a canopy into sunlit and shaded leaf types (Sinclair et al. 1976; De Pury and Farquhar 1997). The latter approach can use either single or multiple layers with canopy leaf area index (LAI) in each layer(s) partitioned into sunlit and shade leaf fractions; typically the fraction of sunlit leaves decreases going from top to bottom canopy layers (De Pury and Farquhar 1997). Most mechanistic models use a variety of big-leaf or sun/shade leaf schemes, which in some cases have the framework to incorporate vertical gradients of canopy structural (Hammer and Wright, 1994) and leaf biochemical traits throughout the crop life cycle, the latter especially via relationship with the canopy leaf nitrogen profile (de Pury and Farquhar, 1997). Additionally 
to these consolidated state-of-the-art approaches, in more recent years new schemes that connect biochemical processes with crop growth and development dynamics are getting traction (e.g., (Yin and van Laar 2005; Parent et al. 2015; Wu et al. 2016)). Although key to guide modelling efforts, there is to our knowledge a shortage of experimental studies quantifying changes of multiple leaf traits in field crops in function of leaf position and at different times during the season. Most previous studies focused on nitrogen reallocation within the crop canopy (Pons and Pearcy 1994; Vos and van der Putten 2001), with a few metaanalysis studies tackling multiple species and traits worldwide (e.g., see Niinemets et al. 2015). In this study, we report on experimental observations of leaf photosynthetic traits for two crop types, winter barley (Hordeum vulgare L.) and rape seed (Brassica napus L.), with contrasting canopy architecture, at two positions, canopy top and bottom, and over the growing season. We hypothesize that leaf position in these crop types influences photosynthesis and related leaf traits and that bottom leaves provide an important contribution to total canopy photosynthesis, often overlooked in approaches estimating total photosynthesis based on top leaves only. Our objectives thus are: (1) to understand how leaf position within the canopy, linked with the light regime experienced by a leaf, influences photosynthesis and underlying traits in barley and rape seed cropping-systems over the season; and (2) to assess whether differentiating top and bottom leaves, and thus partitioning the canopy to specifically account for the contribution of the bottom part throughout the season, improves the estimation of total canopy photosynthesis. To tackle the second objective, we apply simple upscaling schemes. It should be noted that the aim of this study is not to develop a new upscaling scheme requiring additional field measurements. We farther compare our simple upscaling schemes with an approach typically used with satellite based remote sensing observations and employing the RUE concept. To this regard we are particularly interested to evaluate whether nonlinear processes such as leaf photosynthesis response to light can effectively be linearized if integrated over longer time scales.

\section{Methods}

\subsection{Study site and sampling scheme}

The study was conducted at the arable field site near the town of Oensingen (47 $17^{\prime} 11.1^{\prime \prime} \mathrm{N}$, $7^{\circ} 44^{\prime} 01.5$ " E, $452 \mathrm{~m}$ a.s.l.) on the Central Swiss Plateau, one of the most productive agricultural regions of Switzerland. The cropland is managed under the regulations of the Proof of Ecological Performance (PEP), with a crop rotation mainly focusing on winter wheat, alternating with winter barley, rape seed, peas, potatoes and intermediate cover crops (Emmel et al. 2017). The climate is temperate continental, with annual rainfall of $1100 \mathrm{~mm}$ and an average annual temperature of $9^{\circ} \mathrm{C}$.

A field campaign took place during the 2015 growing season on the main field (CH-Oe2) planted with winter barley (Hordeum vulgare L.), and on the adjacent field where rape seed was grown (Brassica napus L.). Sowing occurred at the beginning (06/09/2014) and at the end (29/09/2014) of September of the previous year for rape seed and barley, respectively; harvest took place beginning of July (04/07/2015) for barley and mid of July (17/07/2015) for rape seed. Measurements started in mid of April when canopies reached a height of $25 \mathrm{~cm}$, which allowed partitioning into a top and a bottom canopy layer, and continued at weekly intervals until the lower canopy started senescing in the beginning of June.

The spatial sampling in both fields included one transect for leaf-level measurements and one parallel transect for leaf area index (LAI) measurements (Fig. 1). Leaf-level measurements were taken at five locations along the transect, each $5 \mathrm{~m}$ apart, and at two canopy heights. The definition of a top and a bottom canopy was based on its partitioning into two layers of equal vertical extent. At each location along the transect one attached healthy, green, fully expanded leaf was measured at each height. Measurements included i) optical leaf properties using an 

curves using a LI-6400 portable gas exchange system (LI-COR, Lincoln, NB, USA); and iii) leaf chlorophyll (Chl) content using the chlorophyll content meter (CCM-300, Opti-Sciences for i) LAI determination using scans and subsequent image analysis with the ImageJ-based software Fiji (ImageJ Version 2.0.0, ); ii) dry weight determination following drying leaves in an oven for 48 hours at $55^{\circ} \mathrm{C}$; and iii) measurement of $\mathrm{C}$ and $\mathrm{N}$ elemental content. The measurement of the elemental carbon (\% C) and elemental nitrogen $(\% \mathrm{~N})$ content was performed using a Flash EA 1112 Series elemental analyzer (Thermo Italy,

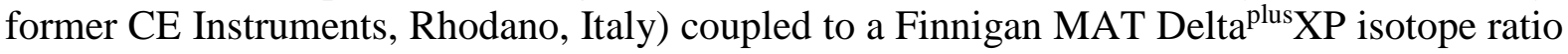
mass spectrometer (Finnigan MAT, Bremen, Germany) as described by Brooks et al. (2003) and . LAI measurements were taken at ten locations along the second transect, each $5 \mathrm{~m}$ apart, and at five equally spaced heights within the canopy (5, 30, 55, 80 and $105 \mathrm{~cm}$ above ground for barley, and 5, 35, 65, 95, $125 \mathrm{~cm}$ for rape seed) using a LAI-2000 Plant Canopy Analyzer (LI-COR) under mostly overcast conditions. A $90^{\circ}$ view cap was used for the LAI-2000 measurements. Top measurements were repeated at every point along the transect, or every second, depending on the stability of the illumination conditions.

In addition to measurements performed at regular intervals during the 2015 field campaign, the Oensingen research site (CH-Oe2) features a closed-path eddy covariance (EC) system for continuous gas exchange and climatological measurements since December 2003. The EC system consists of an R3-50 three-dimensional ultrasonic anemometer (Gill Instruments Ltd., Lymington, Hampshire, UK) and a LI-7500 open-path infrared gas analyser (LI-COR), both delivering data at $20 \mathrm{~Hz}$. Since 2014, a Unispec-DC dual channel spectro-radiometer (PPSystems, Amesbury, MA, USA) measuring incoming light and light reflected by the underlying vegetation in 256 contiguous bands $(350-1200 \mathrm{~nm})$ is operational at the site.

\section{Fig 1. Here}

\subsection{Photosynthetically active radiation measurements}

At the beginning of the 2015 growing season two stationary profile systems measuring photosynthetically active radiation (PAR) located at five different heights were installed at a representative location within the barley and the rape seed fields. Each system consisted of five SQ-110 quantum sensors (Apogee Instruments Inc., Logan, Utah, USA) and a CR10X data logger (Campbell Scientific Inc., Logan, UT, USA). Measurement heights above ground corresponded to those at which LAI measurements were taken (barley: 5, 30, 55, 80, $105 \mathrm{~cm}$; rape seed: $5,35,65,95,125 \mathrm{~cm}$ ). The upwards facing sensors were installed on the south side of the boom and slightly offsetted to avoid self-shading. Measurements were made every second and recorded as 1-minute averages with standard deviations. The PAR sensors were calibrated using a reference PAR lite photosynthetic active radiometer (Kipp \& Zonen, Delft, The Netherlands).

To verify field horizontal homogeneity and representativeness of measurements by the stationary profile systems, two additional mobile PAR profile systems were installed at other locations in the fields for shorter periods during the growing season. The within-field intercomparison provided enough confidence for the use of one system (data not shown).

Continuous light penetration profiles for both crop fields were obtained by iteratively fitting a logistic function of height to the minute resolution data acquired by the stationary PAR profile systems. In a second step, continuous light penetration profiles were spatially integrated (i.e., vertically) for each of the two canopy layers, i.e., top and bottom canopy, using daily canopy height measurements that allowed to estimate the PAR absorbed by each layer at hourly, daily and weekly resolutions. 


\subsection{Leaf-level photosynthesis measurements}

Net photosynthesis light response curves (LRCs) were measured on selected leaves using the LI-6400 portable gas exchange system and the standard leaf chamber with the 6400-02B red/blue LED source. Leaves were placed into the LI-6400 leaf chamber at environmental conditions controlled for temperature, set to optimal $20^{\circ} \mathrm{C}$, and $\mathrm{CO}_{2}$, set to ambient $400 \mu \mathrm{mol}$ $\mathrm{mol}^{-1}$. Flow rate was set to $500 \mu \mathrm{mol} \mathrm{s}{ }^{-1}$. Humidity was monitored throughout the measurements and regulated through manual scrubbing to keep it around 65\%. LRCs were measured going from light to dark, i.e., leaves were equilibrated to high PAR $\left(2000 \mu \mathrm{mol} \mathrm{m}{ }^{-2}\right.$ $\left.\mathrm{s}^{-1}\right)$, followed by a stepwise decrease of PAR down to zero $(1800,1500,1000,800,600,400$, $200,100,50,0 \mu \mathrm{mol} \mathrm{m} \mathrm{m}^{-2} \mathrm{~s}^{-1}$ ). The leaf was given enough time to equilibrate at each light level following pre-set stability criteria. The field campaign started several weeks after the beginning of the growing season when leaves had already acclimated to high light levels. Thus going from high to low light levels was not expected to result in saturation of the photosynthetic pathway, which earlier in the season could instead lead to non-photochemical quenching. Moreover, tests on field-grown plants in a previous study (Singsaas et al. 2001) found that starting LRC at low light could lead to limitation of photosynthesis at high light due to insufficient stomatal opening.

The photosynthesis rate as a function of absorbed light was described using the Mitscherlich response model (Mitscherlich 1928) as:

$$
\mathrm{An}=(\operatorname{Amax}+\mathrm{Rd})\left(1-\exp \left(\frac{-\phi \mathrm{APAR}}{\mathrm{Amax}+\mathrm{Rd}}\right)\right)-\mathrm{Rd}
$$

In Eq. 1, An is net photosynthesis and APAR is the incident light corrected for the absorption capacity of the specific leaf. APAR is the closest estimate of light between $400-700 \mathrm{~nm}$ truly absorbed by the leaf. It is often approximated as equivalent to the incident light but in reality amounts to ca. $80 \%$ of it and varies in function of biochemical and structural leaf traits. Leaf APAR was estimated by measuring optical leaf properties, i.e., leaf reflectance and transmittance spectra, using the ASD Field Spectrometer and a leaf clip with an built-in halogen light source. Ten spectra were averaged per measurement and the leaf absorbance spectrum was calculated from the reflectance and transmittance spectra. Values of incident light by the embedded LI-6400 Red/Blue LED source were subsequently corrected by the derived leaf spectral absorption coefficients. Physiological leaf traits were parametrized in the Mitscherlich model (Eq. 1) as $\phi$, the slope of the linear part of the light response curve, also called apparent quantum yield; Amax, the asymptote representing photosynthesis at light saturation, also called maximum photosynthetic capacity, and Rd, the dark respiration rate. The Mitscherlich model was chosen because its variables have a physiological meaning. Curve fitting was done using a nonlinear least squares procedure, and variables ( $\phi$, Amax, Rd) were extracted for each curve. The sample size for each date and at each of the two canopy heights was of five leaves, corresponding to the five locations along the transect. Variables were estimated for each leaf and, only in a second step, averaged to obtain representative field level estimates for top and bottom canopy leaves, as well as over time since no clear seasonal trend was identified for the investigated time window.

\subsection{Estimations of canopy photosynthesis from leaf-level measurements}

\subsubsection{Leaf-to-canopy photosynthesis upscaling schemes}

Four different leaf-to-canopy photosynthesis upscaling schemes were evaluated (Table 1). Each scheme is distinct in the way it deals with two aspects: 1) the relationship between photosynthesis response and light; and 2) the variation of leaf traits within a canopy.

For the first aspect, we evaluated upscaling approaches based on linear and nonlinear photosynthesis responses to light. While nonlinear approaches draw their rationale from the 
relationship between photosynthesis and absorbed light at the leaf scale, known to be strongly nonlinear, linear approaches are based on the RUE concept introduced by Monteith (1972). In the present study, the RUE term is defined as the $\mathrm{C}$ uptake (defined as gross primary production, GPP) divided by the irradiance (defined as absorbed PAR) (Gitelson and Gamon 2015).

For the second aspect, we compared upscaling schemes partitioning the canopy into a top and a bottom layer, referred to as top/bottom-leaf models, with those that consider the canopy as a single entity, referred to as one-leaf models. In all cases, gross leaf-level photosynthesis was obtained as the sum of net photosynthesis $\left(A_{n}\right)$ and dark respiration $(R d)$.

Table 1. here

\subsubsection{Leaf Area Index for leaf-to-canopy photosynthesis upscaling}

The LAI-2000 plant canopy analyzer was used in this study for the derivation of discrete LAI and mean leaf tilt angle (MTA) values. Measurements above and below a canopy layer were used to determine the canopy gap fraction, from which the LAI and MTA are computed (Lang 1986; Gonsamo et al. 2018).

Continuous LAI time series for top and bottom canopy layers, used for the upscaling of leaf photosynthesis to canopy level, were derived by combining temporally discrete LAI measurements performed at five heights within the canopy with the continuous light penetration estimates from PAR profiles (see section 2.2). A four-step procedure was adopted as follows: (i) height-specific relative PAR time series were obtained by dividing daily average PAR values at the specific height by the incoming daily average PAR at top of the canopy, to which a double logistic function of time was fitted; (ii) the light extinction coefficient for each cumulative layer was derived by an iterative search for the denominator that minimized the difference between the fitted daily relative PAR time series and the corresponding discrete LAI measurements (this resulted in the continuous cumulative LAI time series for the four layers 0-100 cm, 25-100 cm, 50-100 cm, 75-100 cm); (iii) continuous vertical profiles of cumulative LAI for each single day were obtained by fitting a logistic function of canopy depths to the cumulative LAI values; (iv) top and bottom canopy LAI time series were estimated by integrating continuous vertical profiles of cumulative LAI within the extents corresponding to the top and to the bottom canopy layers. Measurements of canopy height were used to determine the extents of top and bottom canopy in time.

\subsection{Approaches to estimate gross photosynthesis productivity}

\subsubsection{Eddy covariance (EC) technique}

GPP from EC was calculated based on a hyperbolic light response curve fit to daytime net ecosystem $\mathrm{CO}_{2}$ exchange (NEE) measured at the flux tower site (i.e., $\mathrm{CH}-\mathrm{Oe2}$ ), modified to account for the temperature sensitivity of respiration and the vapor pressure deficit (VPD) limitation of photosynthesis (Lasslop et al. 2010). The partitioning was done with the $\mathrm{R}$ package, REddyProc, by MPI Jena. When observations were not available, gap-filled data were generated using the Marginal Distribution Sampling (MDS) method, i.e., a moving look-up table technique that uses similar meteorological conditions (of a fixed margin) sampled in the temporal vicinity of the gap to be filled (Moffat et al. 2007).

\subsubsection{Remote sensing}

GPP from spectral measurements was estimated using an approach in line with those commonly adopted by Production Efficiency Models (PEMs) in satellite-based studies. Specifically, we followed the MODIS GPP (MOD17) model (Running et al. 2004):

$$
\mathrm{GPP}=\varepsilon_{\text {max }} \times \mathrm{TMIN}_{\mathrm{s}} \times \mathrm{VPD}_{\mathrm{s}} \times \mathrm{PAR} \times \mathrm{FPAR}
$$


where $\varepsilon_{\max }\left(\mathrm{gC} \mathrm{MJ}^{-1}\right)$ is the maximum RUE when the environment is not limiting for plant $\mathrm{CO}_{2}$ uptake. $\mathrm{TMIN}_{\mathrm{s}}$ and $\mathrm{VPD}_{\mathrm{s}}$ are the attenuation scalars for the daily minimum temperature (TMIN) and daily VPD. These scalars vary linearly between 0 and 1 as a consequence of suboptimal temperature and water availability. For example, high VPD is known to induce stomata closure while low temperatures are known to inhibit the photosynthesis process in many species. The values of the scalars were computed with the following simple linear ramp functions:

$T M I N_{S}=\frac{T M I N-T M I N_{\min }}{T M I N_{\max }-T M I N_{\min }}$

$V P D_{s}=\frac{V P D_{\max }-V P D}{V P D_{\max }-V P D_{\min }}$

where $\mathrm{TMIN}_{\max }$ and $\mathrm{TMIN}_{\min }$ are daily minimum temperatures at $\varepsilon=\varepsilon_{\max }$ and $\varepsilon=0$, respectively; and $\mathrm{VPD}_{\max }$ and $\mathrm{VPD}_{\min }$ are daylight vapor pressure deficits at $\varepsilon=0$ and $\varepsilon=\varepsilon_{\max }$, respectively. The MOD17 type of model employs specific parameters available from the Biome-Properties-Look-Up-Table (BPLUT) for each biome category. For cropland in MOD17 Collection 5.1, the $\varepsilon_{\max }$, TMIN $\mathrm{TMin}_{\min }, \mathrm{TMIN}_{\max }, \mathrm{VPD}_{\min }$, and $\mathrm{VPD}_{\max }$ are defaulted as $1.044 \mathrm{gC}$ $\mathrm{MJ}^{-1},-8.00^{\circ} \mathrm{C}, 12.02^{\circ} \mathrm{C}, 650 \mathrm{~Pa}$, and $4300 \mathrm{~Pa}$, respectively (Zhao and Running 2010). PAR is given by the photosynthetically active radiation incident on the canopy for which above canopy PAR profile measurements are used. FPAR (dimensionless) is the fraction of incident PAR absorbed by the canopy, which we approximate with the normalized difference vegetation index (NDVI) derived from reflectance spectra obtained from UniSpec-DC measurements (Gitelson et al. 2014).

\subsection{Leaf photosynthesis traits as a function of leaf position}

We assessed top and bottom canopy differences in eight key leaf structural (leaf mass per unit area, LMA; leaf area per leaf, LA; leaf mean tilt angle, MTA), chemical (N, C and chlorophyll, Chl, contents) and physiological (quantum yield, $\phi$; maximum photosynthetic capacity, Amax; dark respiration, Rd) traits that play an important role in photosynthesis dynamics. For both crops, barley and rape seed, traits differed between top and bottom leaves, with top leaves showing consistently higher values, with the only exception of $\phi$ and LA, which were higher for bottom leaves (Fig. 2). These leaf position dependent patterns remained mostly stable throughout the measurement campaign of ca. 1.5 months, between mid of April and beginning of June 2015, leading up to ripening and senescence of the crops. A two-sample t-test examining the significance of differences between top and bottom canopy leaves, resulted in the null hypothesis of equal means of top and bottom leaves being rejected for all of the variables with a two-tailed 95\% confidence level (Table S1). Amax showed the most significant difference among the physiological traits $(p=0.0009$ for barley; $p=0.001$ for rape seed), while leaf $\mathrm{N}$ content showed the most significant differences among the chemical traits ( $p<0.00001$ for barley; $\mathrm{p}=0.006$ for rape seed). Evidence of statistically significant differences between rape seed top and bottom leaves was not found for leaf Chl content, LMA and MTA. Lack of significance was also found for barley LA, albeit bottom leaves showing consistently higher values except at the start of the seasons.

Seasonal variations in leaf traits within the measurement period were observed but did not show a clear seasonal trend. Rape seed leaf traits for which a seasonal trend was most pronounced were Rd, dropping from 2.3 to $0.7 \mu \mathrm{mol}$ (bottom) and from 4 to $0.9 \mu \mathrm{mol}$ (top), and $\mathrm{N}$ content, dropping from 2.6 to $1.5 \mathrm{~g}$ (bottom) and from 4.3 to $1.6 \mathrm{~g}$ (top), within one month from end of April to end of May. Mostly however, seasonal differences were smaller than differences found between top and bottom leaves (Fig. 2). Therefore, seasonal mean 
values of Amax, $\phi$ and Rd, were used in this study for leaf-to-canopy photosynthesis upscaling schemes.

\section{Fig 2. Here}

\subsection{Top and bottom leaves contributions to total canopy photosynthesis}

In the measurement period, the amount of light absorbed by the bottom half of the barley canopy always exceeded that absorbed by the top half. The relative fraction of light absorbed by the top canopy increased through the season in response to increasing LAI in the corresponding top layer (inset Fig 3). On April 29, the bottom canopy absorbed $80 \%$ of total daily PAR, with a LAI value of 3.6 against a LAI of 0.5 for the top layer. More than a month later on June 5, the bottom canopy absorbed only 54\% of the PAR with a LAI value of 1.8 against a LAI of 2.0 for the top layer (Fig. 3, top panels). Contributions of top and bottom layers to total barley canopy photosynthesis followed a similar trend, with a steady decrease in bottom canopy contribution to total canopy photosynthesis: 89\% on April 29, 82\% on May 8, $51 \%$ on May 22 and only 36\% on June 5. Diurnal courses of GPP up-scaled from exact-day leaf-level measurements using the top/bottom-leaf scheme compare remarkably well with measured GPP, with the exception of the time interval around noon on June $5^{\text {th }}$ when up-scaled estimates seem to underestimate GPP (Fig. 3). For the same day a better match was found with EC estimated GPP, when using seasonal mean values of Amax, $\phi$ and Rd, with the top/bottomleaf upscaling scheme (see Fig. 4). We thus hypothesize that this is due to the specific Amax parameter measured on June $5^{\text {th }}$ that was either underestimated or measured for leaves not representative of overall field conditions. Worth noting is also the mid-day depression in upscaled total canopy GPP on June $5^{\text {th }}$ (Fig. 3) and some other dates (Fig. 4). This underestimation could be related to lower noon time PAR absorbed by the top canopy layer (top panel in Fig. 3), which is caused by mostly vertical leaf angles of barley which aligns with noon time solar rays, resulting in lower radiation interception area. An alternative explanation for this recurrent feature is that some of the bottom leaves have top-canopy traits because they have access to sunflecks.

Fig 3. Here

Fig 4. Here

\subsection{Linearity of photosynthesis response to light}

Adjusted r-square was used to assess the linearity of the photosynthesis response to light for leaves at the top and at the bottom of the barley and rape seed canopies. For both crop types, integrating from hourly to daily temporal resolutions increased the linearity of top leaves' photosynthesis response, with changes in APAR explaining over 93\% and over $91 \%$ of the variation for barley and rape seed leaves, respectively (Fig 5). At weekly temporal resolution, the effect of light saturation on bottom leaves was most evident, resulting in the lowest adjusted r-square (barley: 0.33; rape seed: 0.24) (Fig. 5).

\section{Fig 5. Here}

\subsection{Leaf-to-canopy photosynthesis upscaling schemes}

Four different leaf-to-canopy photosynthesis upscaling schemes were evaluated in this study. Table 2 presents the complete set of coefficients to derive leaf-level photosynthesis rate for barley and rape seed leaves starting from measurements or estimates of PAR absorbed by green fully expanded leaves.

\section{Table 2. Here}


For barley, photosynthesis upscaling schemes were evaluated against total GPP derived from EC flux measurements at daily and weekly temporal resolutions. If we consider overall performance, including the explained variance by adjusted $r^{2}$ and total errors by RMSE and bias, top/bottom-leaf schemes performed better than one-leaf schemes for both LRC and RUE models (Fig. 6). Between the two, LRC overall performed better than RUE models, in that LRC resulted in lower bias and RMSE magnitudes than RUE at each temporal resolution whilst both explained the observed variance significantly $(\mathrm{p}<0.001)$ at daily time scales (Fig. 6). The comparison is limited to daily and weekly temporal resolutions since RUE type models are not intended for hourly simulations.

\section{Fig 6. Here}

\subsection{Comparison with MODIS satellite GPP approach}

RUE models are at the base of photosynthesis models relying on remote sensing datasets. Among the most commonly used satellite-based GPP products is the moderate-resolution imaging spectroradiometer (MODIS) GPP product (MOD17) (Running et al. 2004). In the current study, we have applied a ground-based version of the MOD17 algorithm in which FPAR is approximated with the NDVI derived from reflectance spectra measured with a UniSpec-DC. The MODIS-GPP ground (MOD17gr) and the two best performing leaf-tocanopy upscaling schemes, i.e., $\mathrm{LRC}_{\mathrm{tb}}$ and $\mathrm{LRC}_{1 \mathrm{~L}}$, are compared over time and against EC GPP at daily time scales in Fig. 7. GPP was largely underestimated by the MOD17gr model, whereas GPP estimates obtained with the $\mathrm{LRC}_{\mathrm{tb}}$ upscaling scheme best matched the EC GPP estimates, but were prone to a slight overestimation throughout the measurement period.

Fig 7.

\section{Discussion}

\subsection{Photosynthesis trait variation as function of leaf position and crop type}

The first objective of this study was to understand how leaf position within the canopy, linked with the light regime experienced by a leaf, influences leaf photosynthesis and underlying traits. We found top and bottom leaves differed in terms of photosynthesis and underlying biochemical, structural and physiological leaf traits in both, winter barley and rape seed crop types. Differences along crop growth stage were not consistent throughout the measuring period and a clear seasonal trend could not be identified (Fig. 2).

Top canopy leaves evidenced significantly higher Amax and Rd than bottom canopy leaves, a typical adaptation to high light environments. Whereas bottom canopy leaves were found having higher quantum yield $(\phi)$ and thus deal more efficiently with low diffuse light conditions they are adapted to. While the theoretical maximum quantum yield $\left(\phi_{\max }\right)$ was reported to be 0.125 in the absence of photorespiration, with 8 moles of photons required to reduce 1 mole of $\mathrm{CO}_{2}$ (Long et al. 1993), photosynthesis studies report measured values to be 30-50\% lower than the theoretical maximum (Singsaas et al. 2001). This is in agreement with our findings; an exception is given by rape seed bottom leaves for which higher values $(0.103$ \pm 0.027 ) were measured in the field. Considerable variation in measured $\phi$ values is however still found in the literature and is mostly ascribed to plants experiencing different levels of environmental stress (Björkman 1981; Singsaas et al. 2001) and/or as a consequence of leaves acclimation to different spectral composition of the light environment (Hogewoning et al. 2012).

Interestingly, while top and bottom leaf values of Amax and $\phi$ differed considerably between barley and rape seed, the rate of down-regulation in response to canopy position (proportional decrease in Amax or increase in $\phi$ relative to the value of the top position) was similar between crop types. Amax of top leaves was 1.8 times higher and $\phi$ was 1.2 times lower 
than for bottom leaves for both, rape seed and barley leaves. This suggests that despite differences in crops canopy architectures resulting in different light availabilities and interception within canopies, simple down-regulation functions accounting for leaf position might be applicable, although further testing would be required. A study looking at gradients of maximum photosynthetic capacity and respiration rates for saplings of six temperate tree species, found that the rate of down-regulation in response to shade was not significantly species- or taxon-specific, nor was it different between sun-grown plants and shade-grown plants (Chen et al. 2014). The authors (Chen et al. 2014) attributed most of the down-regulation of per unit area Rd and Amax to reductions in LMA, i.e., leaves getting thinner as light decreases, while per unit mass Amax and Rd remained nearly constant. Contrary to this finding by Chen and co-authors (2014), our data shows that Amax and Rd per unit mass remains higher $(\mathrm{p}<0.05)$ for top over bottom leaves for both crop types (not presented here for brevity). As already discussed in the introduction, fast-return species such as crops follow completely different patterns of growths and development. In our study, LMA seems to have a less important role as compared to $\mathrm{N}$ in driving the down-regulation of photosynthesis with increasing canopy depth. Although, in average over the season LMA is higher for top leaves as compared to bottom leaves, this difference was not significant for rape seed (Fig. 2). Typically top leaves, experiencing a higher degree of direct collimated light, are thicker because their anatomy is characterized by the presence of columnar palisade cells which facilitate the penetration of the direct collimated light component and the more equal distribution of light to chloroplasts deeper within the leaf (Vogelmann and Martin 1993). However, in crops top leaves are in an earlier developmental stage and have not accumulated dry matter by the time they occupy the top most sunlit position in the canopy.

On the other hand, nitrogen reallocation is a faster mechanism adopted by crop species to maximize whole-plant canopy photosynthesis at a given resource availability. Nitrogen concentrations have been shown to increase from bottom to top of the canopy, where ample light is available for higher photosynthetic C fixation (Pons and Pearcy 1994; Vos and van der Putten 2001; Niinemets et al. 2015; Niinemets 2016). To understand potential environmental constraints on photosynthesis at a specific leaf position we looked at the ratio between the chlorophyll concentration and the total amount of nitrogen in the leaves (chlorophyll per nitrogen, $\mathrm{Chl} / \mathrm{N}$ ). The higher $\mathrm{Chl} / \mathrm{N}$ ratio for bottom leaves for both crop species pointed to leaves limited by light capture (high $\mathrm{Chl} / \mathrm{N}$ ) rather than $\mathrm{CO}_{2}$ assimilation (low $\mathrm{Chl} / \mathrm{N}$ ) in the bottom half of the canopy. This despite top leaves being still characterized by higher Chl levels overall.

These leaf-level traits variations however provide only a partial picture and need to be combined with canopy structure and crop growth and development information to gain a better understanding of total canopy photosynthesis dynamics.

\subsection{Implications of leaf position for canopy photosynthesis modelling}

The second objective of this study was assessing whether differentiating between top and bottom leaves improves the estimation of total canopy photosynthesis. It should be noted that the top/bottom-leaf dichotomy adopted here distinguishes top from bottom leaves and is thus different from the sunlit vs. shaded leaf dichotomy adopted in sun/shade scheme and amply discussed by De Pury and Farquhar (1997). Although the top and bottom halves of the canopy are typically associated with high and low light conditions, respectively, this does not necessary translate into the same partitioning of absorbed PAR. We found that, despite leaf-level maximum photosynthetic capacity (Amax, Fig. 2) being higher for top leaves, the bottom half of the canopy absorbs more light and is thus the major contributor to total canopy photosynthesis for most of the season, until the onset of senescence in the lower canopy (Fig. 
3-4). Under diffuse light conditions typical of overcast days, the contribution of the bottom canopy is higher than that of the top canopy even at the leaf-level, with bottom leaves having higher or comparable net photosynthesis as compared to top leaves (see Fig S1). The following are possible explanations of why the bottom canopy is the major contributor to total canopy photosynthesis. Firstly, before the senescence of the bottom half of the canopy sets-in in late May, the bottom layer is characterized by higher LAI (Fig. 3), due to more leaves with higher leaf area per leaf (LA, Fig. 2). Higher LA and quantum yield $(\phi)$ are the two mechanisms which bottom leaves have adopted to cope with low diffuse light conditions. Secondly, bottom leaves were found having lower mean tilt angles (MTA, Fig. 2), typical of leaves perpendicular to the sun's rays. Leaf angle defines the amount of intercepted irradiance. At the top of the canopy, leaves might adopt angles parallel to the sun's rays and absorb mostly diffuse and scattered irradiance to avoid photodamage during the time of day when the sun is highest above the horizon.

It should be farther noted that especially during the reproductive and senescence stages not all PAR absorbed by the canopy is used for photosynthesis. This is primarily due to seasonal changes in pigment composition, i.e., chlorophyll vs. carotenoid content, relative levels of xanthophyll cycle pigments (Gitelson et al. 2014; Gitelson et al. 2015) and the related excess energy dissipation mechanisms. As evidenced by the drop in Chl content of the bottom half of the barley canopy (Fig. 2), not all APAR might be used for photosynthesis, potentially leading to a slight overestimation of bottom canopy photosynthesis for our very last days of measurements. However, since our measuring period predominantly overlaps with the crop's vegetative stage, potential overestimations can be considered negligible.

We found that the top/bottom-leaf upscaling schemes, separating between top and bottom leaves types, outperformed the one-leaf upscaling scheme when compared with measured GPP. This was particularly evident at high temporal resolutions (from minutes to hours), and less so for resolutions spanning days to weeks (Fig. 6). Nevertheless, for all models, one-leaf schemes exhibited higher errors as compared to their top/bottom-leaf counterparts. Both our one-leaf and top/bottom-leaf upscaling schemes were parameterized directly from leaf-level measurements (Table 1) and thus truly capture leaves biochemical variation within a canopy, however, they require additional field measurements whose collection might not be feasible for broad scale applications. To the best of our knowledge, there are no other studies which separate top and bottom canopy layers based on actual leaf traits so a direct comparison with other studies was not possible.

\subsection{Linearity of photosynthesis light response only observed for top leaves}

Based on the field dataset we also evaluated whether nonlinear processes such as leaf photosynthesis response to light for both, top and bottom leaves, could effectively be linearized if integrated over longer time scales. This is particularly relevant in the context of remote sensing based approaches for GPP estimation, since these commonly combine RUE models and remotely sensed data collected at weekly to bi-weekly intervals. At the base of RUE models first introduced by Monteith (1972) is the finding that a nonlinear process such as the leaf photosynthetic response to light can be linearized if longer time intervals are considered. Among the most credited theories explaining this phenomenon is functional convergence, i.e. the interaction with other resource limitations over time (Field 1991; Goetz and Prince 1999; Medlyn et al. 2003). This theory predicts that, since leaves are expensive to produce and maintain, when plants are nutrient-limited, experiencing drought, or exposed to other adverse conditions, they reduce their leaf area to use resources efficiently, although full optimization might never be truly achieved (Niinemets 2007).

In this study, a linearization of the leaf photosynthesis response to light was observed mainly for top leaves, integrated to daily and to weekly resolutions. Bottom leaves on the other hand 
showed linear responses at daily resolutions, while weekly photosynthetic responses remained nearly constant with changing weekly APAR levels (Fig. 5). This reinforces the use of linear RUE models in concomitance with remotely sensed observations which mainly capture signal from the upper canopy, however at the same time questions their representativeness of total canopy photosynthesis.

At the canopy level, linear RUE models used to upscale leaf-level photosynthesis overestimated GPP for daily and weekly resolutions (Fig. 6). Findings by previous studies suggest that linear models are applicable on time-scales of two weeks and more (Medlyn 1998), however evidence of whether this applies also to the lower half of the canopy is currently missing. On the other hand, the MODIS-GPP ground (MOD17 $\mathrm{gr}$ ) linear model employing a fixed maximum RUE $\left(\varepsilon_{\max }\right)$ term prescribed in the current biome property look-up table (BPLUT), resulted in an underestimation of GPP. There are two possible reasons at the base of this underestimation. The first one is the use of NDVI as a proxy of fAPAR in crops. Although there is ample empirical evidence that fAPAR is related to top of the canopy spectral vegetation indices (VIs), linear relationships are mainly found during the reproductive stages of crops (Gitelson et al. 2014). During the crop's vegetative stage, characterized by moderate-to-high green LAI, in situ measured NDVI has been shown to saturate and underestimate fAPAR in C3 and C4 crops (Asrar 1984; Gallo et al. 1985; Viña 2005). Furthermore, spectral VIs are not able to capture vertical heterogeneity of chlorophyll content and green LAI within the canopy, which is instead accounted for in our top/bottom-leaf upscaling approach, separating top and bottom leaves (Fig. 7). This is a common problem of spectral remote sensing proxies used for the estimation of canopy biochemical, physiological and structural canopy traits (Gitelson et al. 2014). The second reason for the underestimation by the MOD17gr, is seen in the too low $\varepsilon_{\max }$ term for crops used by the MODIS GPP/NPP algorithm (Chen et al. 2011; Bandaru et al. 2013; Xin et al. 2015). Gitelson et al. (2015) found $\varepsilon_{\max }$ to be $50 \%$ higher in C3 soybean and $250 \%$ higher in C4 maize than the value used in the MODIS model. At present, in an effort to generalize model parameterization, the MODIS Land Science Team does not differentiate $\varepsilon_{\max }$ between geographical regions, crop types or spatial scales.

\section{Conclusions}

Results presented in this study contribute to the understanding of biophysical controls on C fluxes in crop ecosystems by investigating the effect of within canopy light regimes on photosynthesis and related traits. Our findings confirm those by previous authors, showing how fast growing species adopt nitrogen and, to a lesser degree, dry matter reallocation strategies to deal with the excess light at the top of their canopies. For both crop types, barley and rape seed, top leaves showed higher photosynthetic capacity, dark respiration, leaf nitrogen, carbon and chlorophyll contents, and leaf mass per area. Whereas bottom leaves showed higher photosynthetic efficiency (i.e., quantum yield) at low light levels. Despite this, the bottom canopy layer remained the main contributor to total canopy photosynthesis until the start of senescence, which progresses upwards from the lower canopy. This is mainly explained by greater radiation interception by the bottom half of the canopy, due to the combined effect of higher leaf area per leaf, more horizontal leaf orientation, and higher photosynthetic efficiency under low light.

We presented our observations in the context of four leaf-to-canopy photosynthesis upscaling schemes. These schemes address the challenge of integration of photosynthesis over time and within the canopy space. Integration of photosynthetic response over time tends to transforms a nonlinear process, such as the leaf photosynthesis response to light, into a linear relationship whose strength increases with the increase of the temporal integration interval. Although not perfectly valid under all conditions, this simplification allows the use of remote sensing based 
approaches to parametrize the linear model either using fixed slope coefficients (e.g., MOD17 product; Running et al. 2004) or vegetation indices that scale with light use photosynthetic efficiency (e.g., PRI; Peñuelas et al. 2011). Top leaves showed a more linear response with light than bottom leaves, while the effect of light saturation on bottom leaves resulted in the lowest linearity. This finding is validating RUE models relying on remotely sensed observations, which predominantly capture signal from the upper canopy. However, it should also raise awareness that such approaches might be underrepresenting bottom canopy traits and photosynthesis. This is especially concerning given the importance of bottom canopy contribution to total canopy photosynthesis shown in this study.

Integration of photosynthesis within the canopy space, was investigated by comparing oneleaf vs. top/bottom-leaf schemes, distinguishing top from bottom leaf types, against EC estimated GPP for barley. Findings showed that top/bottom upscaling schemes, which distinctively account for bottom canopy contribution over the season, generally outperformed one-leaf schemes, highlighting the importance of the bottom canopy. The observed within canopy trait variability and the requirement for additional field measurements, remain an outstanding challenge in the derivation of broadly applicable leaf-to-canopy photosynthesis upscaling schemes. Future research thus must bridge the gap between greater realism, obtained through field measurements, and the model requirements for simplification.

\section{Acknowledgments}

This project was in part funded by the Swiss National Science Foundation (SNF) grant 146373 and the State Secretariat for Education, Research and Innovation (SERI) in the frame of COST Action ES1309 (OPTIMISE). We thank the farmers Daniel and Walter Ingold for the management of the field and for proving information on the management, Agroscope Reckenholz-Tnikon for providing access to the field site and infrastructure. We thank all technicians involved (Thomas Baur, Philip Meier, Florian Kaeslin, Patrick Koller), Eugenie Paul-Limoges and Andreas Hüni from the SEON Project for the installation and the management of the Unispec-DC instrument, and Annika Ackermann for performing the $\mathrm{C}$ and $\mathrm{N}$ elemental analyses. We thank Dr. Anatoly A. Gitelson and two anonymous reviewers for providing valuable comments.

\section{References}

Asrar, G, Fuchs, M., Kanemasu, E. T., \& Hatfield, J. H. (1984) Estimating absorbed photosynthetic radiation and leaf area index from spectral reflectance in wheat. Agronomy Journal 76, 300-306.

Bandaru, V, West, TO, Ricciuto, DM, César Izaurralde, R (2013) Estimating crop net primary production using national inventory data and MODIS-derived parameters. ISPRS Journal of Photogrammetry and Remote Sensing 80, 61-71.

Björkman, O (Ed.) (1981) 'Responses to different quantum flux densities.' In 'Physiological Plant Ecology. I. Responses to the Physical Environment'. (Springer-Verlag: New York)

Blackman, FF (1905) Optima and limiting factors. Annals of Botany 19, 281-295.

Brooks, PD, Geilmann, H, Werner, RA, Brand, WA (2003) Improved precision of coupled $\delta 13 \mathrm{C}$ and $\delta 15 \mathrm{~N}$ measurements from single samples using an elemental analyzer/isotope ratio mass spectrometer combination with a post-column six-port valve and selective CO2 trapping; improved halide robustness of the combustion reactor using CeO2. Rapid Communications in Mass Spectrometry 17, 1924-1926.

Chen, A, Lichstein, JW, Osnas, JLD, Pacala, SW (2014) Species-Independent DownRegulation of Leaf Photosynthesis and Respiration in Response to Shading: Evidence from Six Temperate Tree Species. PLoS ONE 9, 
Chen, J-L, Reynolds, JF, Harley, PC, Tenhunen, JD (1993) Coordination theory of leaf nitrogen distribution in a canopy. Oecologia 93, 63-69.

Chen, T, van der Werf, GR, Dolman, AJ, Groenendijk, M (2011) Evaluation of cropland maximum light use efficiency using eddy flux measurements in North America and Europe. Geophysical Research Letters 38,

Coble, AP, Cavaleri, MA (2015) Light acclimation optimizes leaf functional traits despite height-related constraints in a canopy shading experiment. Oecologia 177, 11311143.

Coble, AP, VanderWall, B, Mau, A, Cavaleri, MA (2016) How vertical patterns in leaf traits shift seasonally and the implications for modeling canopy photosynthesis in a temperate deciduous forest. Tree Physiology 36, 1077-1091.

De Pury, DGG, Farquhar, GD (1997) Simple scaling of photosynthesis from leaves to canopies without the errors of big-leaf models. Plant, Cell \& Environment 20, 537557.

De Wit, CT (1978) Simulation of Assimilation, Respiration and Transpiration of Crops. Wageningen University.

Emmel, C., Winkler, A., Hörtnagl, L., Revill, A., Ammann, C., D'Odorico, P., Buchmann, N., and Eugster, W.: Integrated management of a Swiss cropland is not sufficient to preserve its soil carbon pool in the long term, Biogeosciences, 15, 5377-5393.

Evans, JR, Poorter, H (2001) Photosynthetic acclimation of plants to growth irradiance: the relative importance of specific leaf area and nitrogen partitioning in maximizing carbon gain. Plant, Cell \& Environment 24, 755-767.

Falster, DS, Westoby, M (2003) Leaf size and angle vary widely across species: what consequences for light interception? New Phytologist 158, 509-525.

Farquhar, GD, von Caemmerer, S (1982) Modelling of Photosynthetic Response to Environmental Conditions. In 'Physiological Plant Ecology II: Water Relations and Carbon Assimilation.' (Eds OL Lange, PS Nobel, CB Osmond, H Ziegler.) pp. 549587. (Springer Berlin Heidelberg: Berlin, Heidelberg)

Farquhar, GD, von Caemmerer, S, Berry, JA (1980) A biochemical model of photosynthetic CO2 assimilation in leaves of C3 species. Planta 149, 78-90.

Field, CB (1991) 2 - Ecological Scaling of Carbon Gain to Stress and Resource Availability A2 - Mooney, Harold A. In 'Response of Plants to Multiple Stresses.' (Eds WE Winner, EJ Pell.) pp. 35-65. (Academic Press: San Diego)

Frantz, JM, Joly, RJ, Mitchell, CA (2000) Intracanopy Lighting Influences Radiation Capture, Productivity, and Leaf Senescence in Cowpea Canopies. Journal of the American Society for Horticultural Science 125, 694-701.

Gallo, KP, Daughtry, CST, Bauer, ME (1985) Spectral estimation of absorbed photosynthetically active radiation in corn canopies. Remote Sensing of Environment 17, 221-232.

Gitelson, AA, Gamon, JA (2015) The need for a common basis for defining light-use efficiency: Implications for productivity estimation. Remote Sensing of Environment 156, 196-201.

Gitelson, AA, Peng, Y, Arkebauer, TJ, Suyker, AE (2015) Productivity, absorbed photosynthetically active radiation, and light use efficiency in crops: Implications for remote sensing of crop primary production. Journal of Plant Physiology 177, 100109.

Gitelson, AA, Y. Peng, Huemmrich., KF (2014) Relationship between fraction of radiation absorbed by photosynthesizing maize and soybean canopies and NDVI from remotely sensed data taken at close range and from MODIS $250 \mathrm{~m}$ resolution data. Remote Sensing of Environment 147, 108-120. 
Goetz, SJ, Prince, SD (1999) Modelling Terrestrial Carbon Exchange and Storage: Evidence and Implications of Functional Convergence in Light-use Efficiency. In 'Advances in Ecological Research.' (Eds AH Fitter, D Raffaelli.) Vol. Volume 28 pp. 57-92. (Academic Press:

Gonsamo, A, Pellikka, P (2009) The computation of foliage clumping index using hemispherical photography. Agricultural and Forest Meteorology 149, 1781-1787.

Gonsamo, A, Walter, JM, Chen, JM, Pellikka, P, Schleppi, P (2018) A robust leaf area index algorithm accounting for the expected errors in gap fraction observations. Agricultural and Forest Meteorology 248, 197-204.

Hogewoning, SW, Wientjes, E, Douwstra, P, Trouwborst, G, van Ieperen, W, Croce, R, Harbinson, J (2012) Photosynthetic Quantum Yield Dynamics: From Photosystems to Leaves. The Plant Cell 24, 1921.

Holzworth, DP, Huth, NI, deVoil, PG, Zurcher, EJ, Herrmann, NI, McLean, G, Chenu, K, van Oosterom, EJ, Snow, V, Murphy, C, Moore, AD, Brown, H, Whish, JPM, Verrall, S, Fainges, J, Bell, LW, Peake, AS, Poulton, PL, Hochman, Z, Thorburn, PJ, Gaydon, DS, Dalgliesh, NP, Rodriguez, D, Cox, H, Chapman, S, Doherty, A, Teixeira, E, Sharp, J, Cichota, R, Vogeler, I, Li, FY, Wang, E, Hammer, GL, Robertson, MJ, Dimes, JP, Whitbread, AM, Hunt, J, van Rees, H, McClelland, T, Carberry, PS, Hargreaves, JNG, MacLeod, N, McDonald, C, Harsdorf, J, Wedgwood, S, Keating, BA (2014) APSIM - Evolution towards a new generation of agricultural systems simulation. Environmental Modelling \& Software 62, 327-350.

Husse, S, Huguenin-Elie, O, Buchmann, N, Lüscher, A (2016) Larger yields of mixtures than monocultures of cultivated grassland species match with asynchrony in shoot growth among species but not with increased light interception. Field Crops Research 194, 111.

Jones, JW, Hoogenboom, G, Porter, CH, Boote, KJ, Batchelor, WD, Hunt, LA, Wilkens, PW, Singh, U, Gijsman, AJ, Ritchie, JT (2003) The DSSAT cropping system model. European Journal of Agronomy 18, 235-265.

Kattge, J, Knorr, W, Raddatz, T, Wirth, C (2009) Quantifying photosynthetic capacity and its relationship to leaf nitrogen content for global-scale terrestrial biosphere models. Global Change Biology 15, 976-991.

Lang, ARG (1986) Leaf area and average leaf angle from transmittance of direct sunlight. Australian Journal of Botany 34, 349-355.

Lasslop, G, Reichstein, M, Papale, D, Richardson, AD, Arneth, A, Barr, A, Stoy, P, Wohlfahrt, G (2010) Separation of net ecosystem exchange into assimilation and respiration using a light response curve approach: critical issues and global evaluation. Global Change Biology 16, 187-208.

Leuning, R (1995) A critical appraisal of a combined stomatal-photosynthesis model for C3 plants. Plant, Cell \& Environment 18, 339-355.

Long, SP, Postl, WF, Bolhár-Nordenkampf, HR (1993) Quantum yields for uptake of carbon dioxide in C3 vascular plants of contrasting habitats and taxonomic groupings. Planta 189, 226-234.

Medlyn, B, Barrett, D, Landsberg, J, Sands, P, Clement, R (2003) Conversion of canopy intercepted radiation to photosynthate: review of modelling approaches for regional scales. Functional Plant Biology 30, 153-169.

Medlyn, BE (1998) Physiological basis of the light use efficiency model. Tree Physiology 18, 167-176.

Mitscherlich, EA (1928) Die zweite Annäherung des Wirkungsgesetzes der Wachstumsfaktoren. Zeitschrift für Pflanzenernährung, Düngung, Bodenkunde 12, 273-282. 
Moffat, AM, Papale, D, Reichstein, M, Hollinger, DY, Richardson, AD, Barr, AG, Beckstein, C, Braswell, BH, Churkina, G, Desai, AR, Falge, E, Gove, JH, Heimann, M, Hui, D, Jarvis, AJ, Kattge, J, Noormets, A, Stauch, VJ (2007) Comprehensive comparison of gap-filling techniques for eddy covariance net carbon fluxes. Agricultural and Forest Meteorology 147, 209-232.

Monsi, M, Saeki, T (1953) Über den Lichtfaktor in den Pflanzengesellschaften und seine Bedeutung für die Stoffproduktion. Japanese Journal of Botany 14, 22-52.

Monteith, JL (1972) Solar radiation and productivity in tropical eco- systems. J. Appl. Ecol. 9, 747-766.

Monteith JL, Moss, C (1977) Climate and the Efficiency of Crop Production in Britain [and Discussion]. Philosophical Transactions of the Royal Society of London B, Biological Sciences 281, 277-294.

Niinemets, Ü (1998) Adjustment of foliage structure and function to a canopy light gradient in two co-existing deciduous trees. Variability in leaf inclination angles in relation to petiole morphology. Trees - Structure and Function 12, 446-451.

Niinemets, Ü (2007) Photosynthesis and resource distribution through plant canopies. Plant, Cell \& Environment 30, 1052-1071.

Niinemets, Ü (2016) Leaf age dependent changes in within-canopy variation in leaf functional traits: a meta-analysis. Journal of Plant Research 129, 313-338.

Niinemets, Ü, Keenan, TF, Hallik, L (2015) A worldwide analysis of within-canopy variations in leaf structural, chemical and physiological traits across plant functional types. New Phytologist 205, 973-993.

Norman, JM (1993) Scaling processes between leaf and canopy levels. In 'Scaling Physiological Processes: Leaf to Globe.' (Eds Ehleringer, Field.) pp. 41-76. (Academic Press: San Diego)

Norman, JM, Jarvis, PG (1974) Photosynthesis in Sitka spruce (Picea sitchensis (Bong.) Carr.) III. Measurements of canopy structure and interception of radiation. Journal of Applied Ecology 11, 375-398.

Norman, JM, Welles, JM (1983) Radiative transfer in an array of canopies. . Agronomy Journal 75, 481-488.

Ono, K, Nishi, Y, Watanabe, A, Terashima, I (2008) Possible Mechanisms of Adaptive Leaf Senescence. Plant Biology 3, 234-243.

Parent, B, Shahinnia, F, Maphosa, L, Berger, B, Rabie, H, Chalmers, K, Kovalchuk, A, Langridge, P, Fleury, D (2015) Combining field performance with controlled environment plant imaging to identify the genetic control of growth and transpiration underlying yield response to water-deficit stress in wheat. Journal of Experimental Botany 66, 5481-5492.

Pearcy, RW (1999) Responses of plants to heterogeneous light environments. In 'Handbook of functional plant ecology.' (Ed. FIV Pugnaire, F. .) pp. 269-314. (Marcel Dekker: New York)

Pons, TL, Pearcy, RW (1994) Nitrogen reallocation and photosynthetic acclimation in response to partial shading in soybean plants. Physiologia Plantarum 92, 636-644.

Running, SW, Nemani, RR, Heinsch, FA, Zhao, M, Reeves, M, Hashimoto, H (2004) A continuous satellite-derived measure of global terrestrial primary production. BioScience 54, 547-560.

Sands, P (1995) Modelling Canopy Production. II. From single-leaf photosynthesis parameters to daily canopy photosynthesis. Functional Plant Biology 22, 603-614.

Sellers, PJ, Berry, JA, Collatz, GJ, Field, CB, Hall, FG (1992) Canopy reflectance, photosynthesis, and transpiration. III. A reanalysis using improved leaf models and a new canopy integration scheme. Remote Sensing of Environment 42, 187-216. 
Sinclair, TR, Muchow, RC (1999) Radiation Use Efficiency. In 'Advances in Agronomy.' (Ed. DL Sparks.) Vol. 65 pp. 215-265. (Academic Press:

Sinclair, TR, Murphy, CE, Knoerr, KR (1976) Development and evaluation of simplified models for simulating canopy photosynthesis and transpiration. Journal of Applied Ecology 13, 813-829.

Singsaas, EL, Ort, DR, DeLucia, EH (2001) Variation in measured values of photosynthetic quantum yield in ecophysiological studies. Oecologia 128, 15-23.

Viña, A, and A. A. Gitelson (2005) New developments in the remote estimation of the fraction of absorbed photosynthetically active radiation in crops. Geophysical Research Letters 32,

Vogelmann, TC, Martin, G (1993) The functional significance of palisade tissue: penetration of directional versus diffuse light. Plant, Cell \& Environment 16, 65-72.

von Caemmerer, S (Ed. TiP Science (2000) 'Biochemical Models of Leaf Photosynthesis.' (CSIRO:

von Caemmerer, S, Farquhar, GD (1981) Some relationships between the biochemistry of photosynthesis and the gas exchange of leaves. Planta 153, 376-387.

Vos, J, van der Putten, PEL (2001) Effects of partial shading of the potato plant on photosynthesis of treated leaves, leaf area expansion and allocation of nitrogen and dry matter in component plant parts. European Journal of Agronomy 14, 209-220.

Wright, IJ, Reich, PB, Westoby, M, Ackerly, DD, Baruch, Z, Bongers, F, Cavender-Bares, J, Chapin, T, Cornelissen, JHC, Diemer, M, Flexas, J, Garnier, E, Groom, PK, Gulias, J, Hikosaka, K, Lamont, BB, Lee, T, Lee, W, Lusk, C, Midgley, JJ, Navas, M-L, Niinemets, U, Oleksyn, J, Osada, N, Poorter, H, Poot, P, Prior, L, Pyankov, VI, Roumet, C, Thomas, SC, Tjoelker, MG, Veneklaas, EJ, Villar, R (2004) The worldwide leaf economics spectrum. Nature 428, 821-827.

Wu, A, Song, Y, van Oosterom, EJ, Hammer, GL (2016) Connecting Biochemical Photosynthesis Models with Crop Models to Support Crop Improvement. Frontiers in Plant Science 7, 1518.

Xin, Q, Broich, M, Suyker, AE, Yu, L, Gong, P (2015) Multi-scale evaluation of light use efficiency in MODIS gross primary productivity for croplands in the Midwestern United States. Agricultural and Forest Meteorology 201, 111-119.

Yin, X, van Laar, HH (2005) 'Crop Systems Dynamics: An Ecophysiological Simulation Model of Genotype-by-environment Interactions.' (Wageningen Academic Publications:

Zhao, M, Running, SW (2010) Drought-induced reduction in global terrestrial net primary production from 2000 through 2009. Science 329, 940-943. 


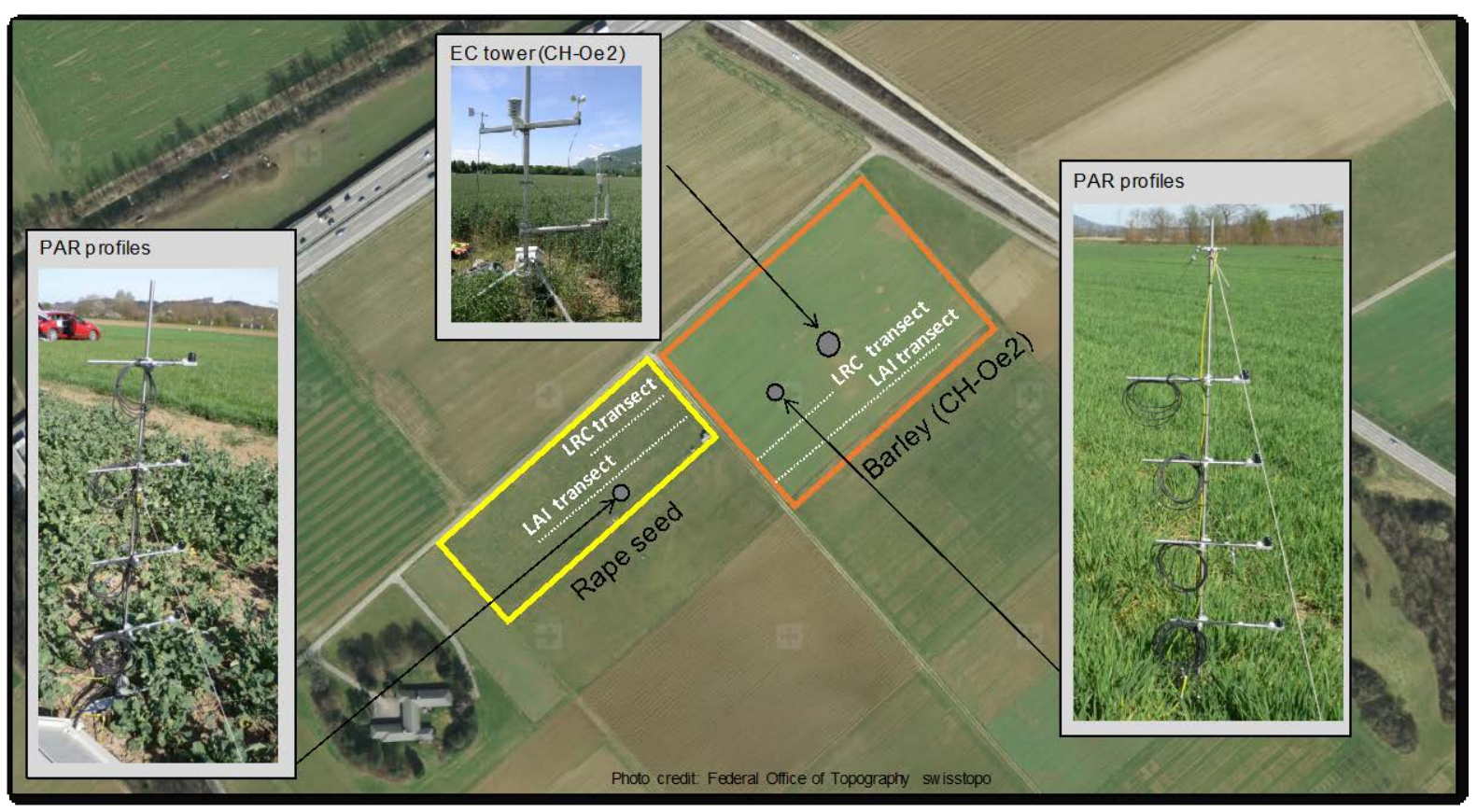

Fig 1. Study site near Oensingen, Switzerland. At the long-term agricultural measurement station $\mathrm{CH}-\mathrm{Oe2}$, greenhouse gas exchange and meteorological variables are continuously measured with the eddy covariance technique. Measurement transects for light response curve (LRC) measurements at two canopy heights as well as leaf area index (LAI) measurements are shown for each field. Location and set-ups of photosynthetically active radiation (PAR) profiles are shown early in a crop seasonal cycle. 

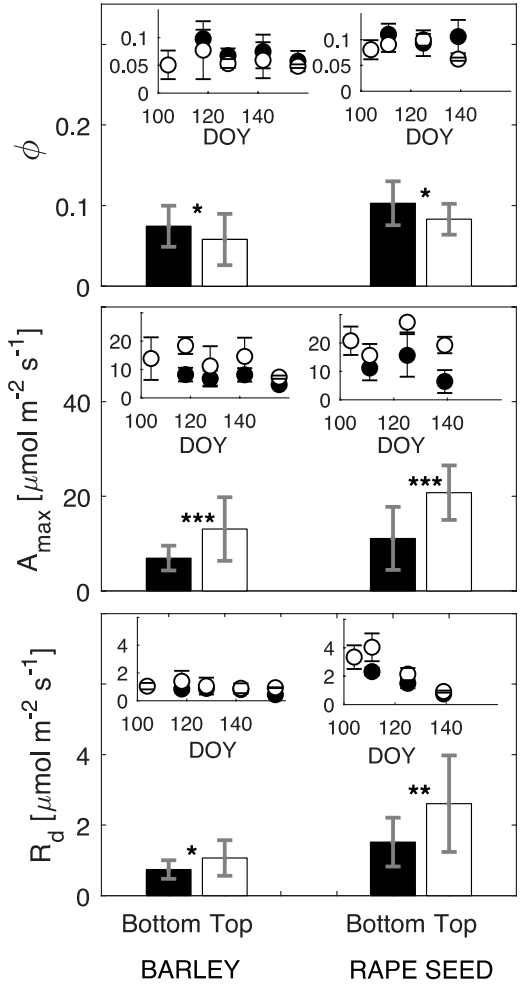

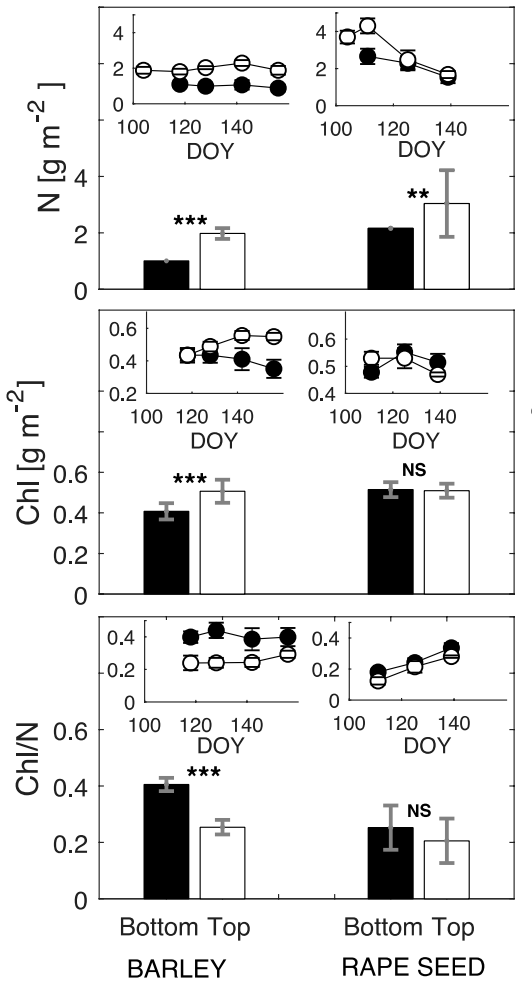

Fig 2. Leaf-level traits: quantum yield $(\phi)$, maximum photosynthetic capacity (Amax), dark respiration $(\mathrm{Rd})$, nitrogen content $(\mathrm{N})$, chlorophyll content (Chl), chlorophyll to nitrogen ratio $(\mathrm{Chl} / \mathrm{N})$, leaf mass per area (LMA), leaf area per leaf (LA) and mean tilt angle (MTA), for barley and rape seed crops, measured for top (white) and bottom (black) canopy leaves. Bar plots represent average variables over the course of the entire growing season with error bars of \pm 1 standard deviation. P-values from a two-tailed test are given as: ${ }^{*}, \mathrm{p} \leqq 0.05$; $* *$, $\mathrm{p} \leqq$ 0.01 ; ***, $\mathrm{p} \leqq 0.001$; NS, not significant. Inset plots show temporal variability over the growing season with error bars of \pm 1 standard deviation representing spatial heterogeneity across the field transect. 


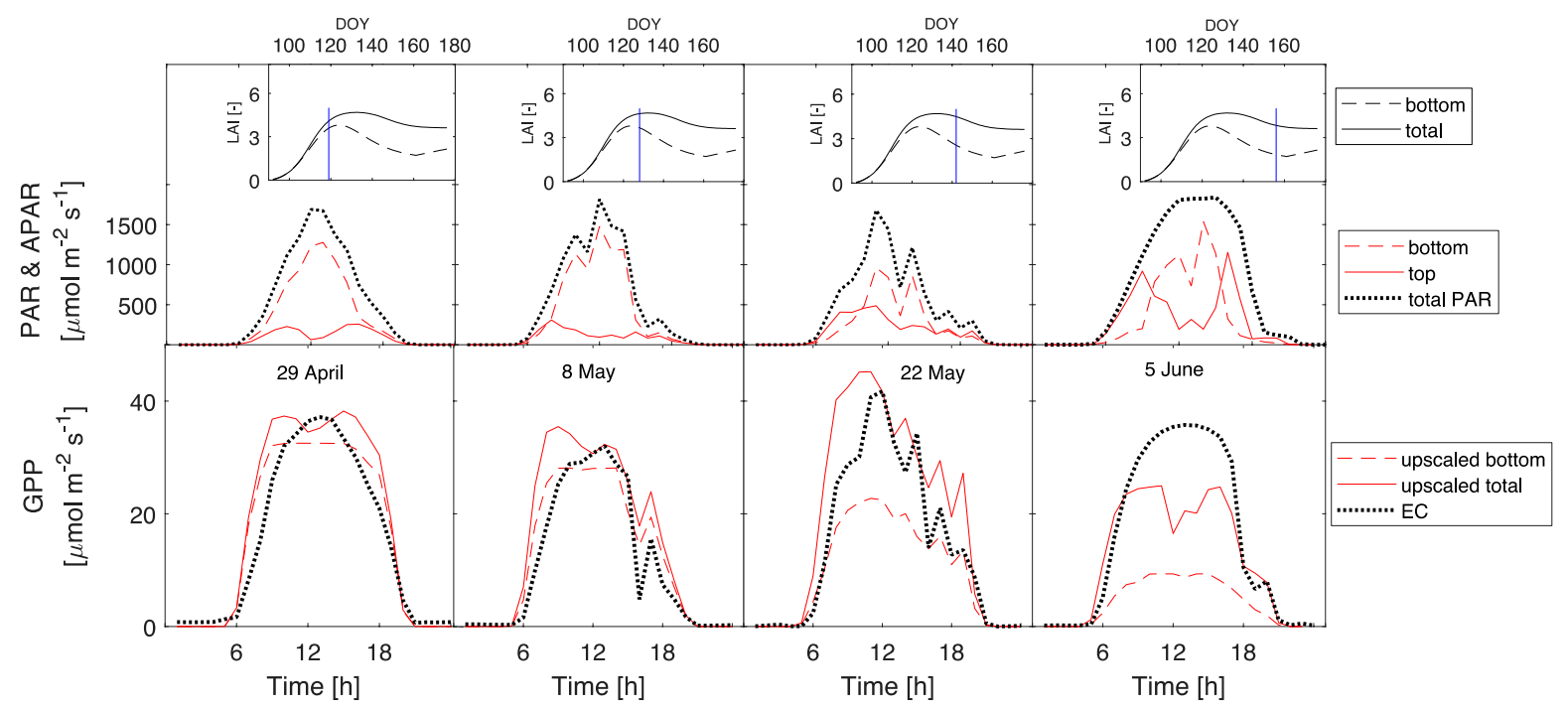

Fig 3. Upper panel: Diurnal courses of incoming photosynthetically active radiation (PAR) (dotted black line), absorbed by top canopy layer (solid red line) and absorbed by bottom canopy layer (dashed red line) of barley crop. Insert: seasonal courses of total canopy leaf area index (LAI) (solid black line) and bottom canopy layer LAI (dashed black line) of barley crop; the exact days corresponding to the plotted PAR, APAR and GPP diurnal courses are indicated by a blue vertical line. Lower panel: Diurnal courses of photosynthesis (GPP) estimated through Eddy Covariance measurements (dotted black line) and upscaled from leaf-level photosynthesis measurements for bottom canopy layer (dashed red line) and for total canopy GPP (solid red line) based on the top/bottom-leaf light response curve scheme. The four days for which the diurnal courses are presented correspond to days with leaf-level photosynthesis and LAI measurement; top and bottom canopy layers are defined as the upper and lower half of the total canopy height, respectively. 


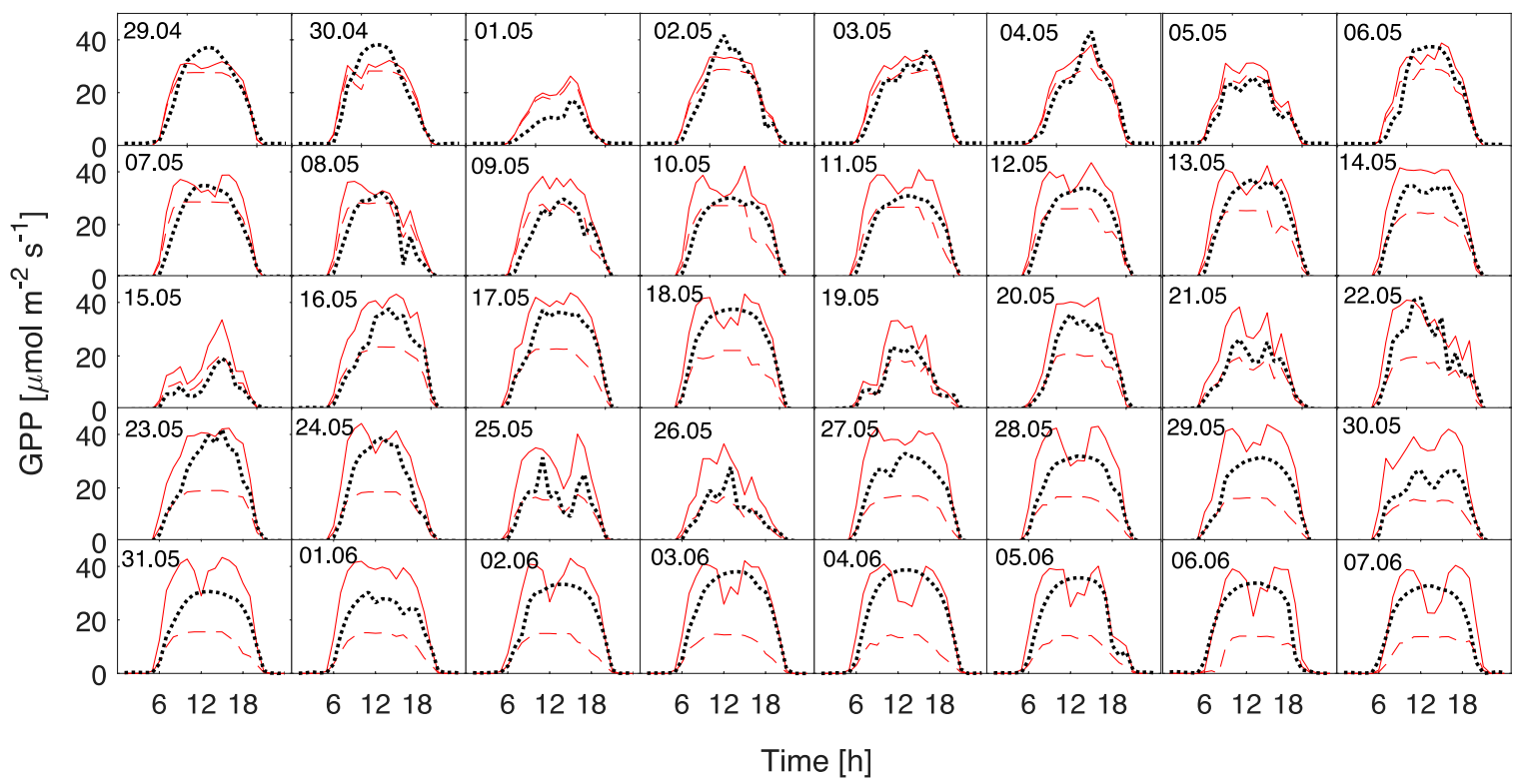

Fig 4. Diurnal courses of barley gross primary production (GPP) derived from eddy covariance measurements (dotted black) and upscaled from leaf-level photosynthesis measurements for the bottom half of the canopy (dashed red) and the total canopy (solid red) based on the top/bottom-leaf light response curve scheme. The seasonal averages of the light response curve parameters (Amax, $\phi$, Rd) were used for all dates. The considered temporal window represents the measurement period from 29 April (plants reached $25 \mathrm{~cm}$ of height) until 7 June (plants senescing). 

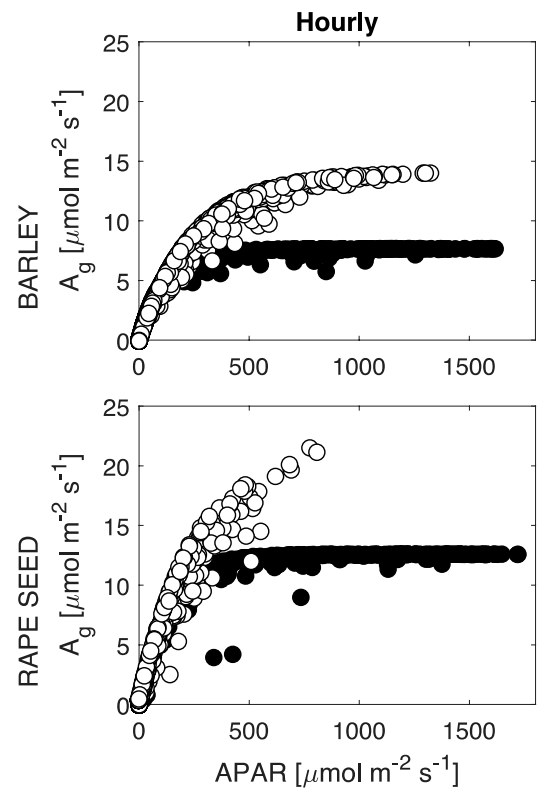

Fig 5. Hourly, daily and weekly relationships between leaf-level gross photosynthesis $\left(A_{g}\right)$ and absorbed photosynthetically active radiation (APAR) at the top (white) and bottom (black) of the barley and rape seed canopies. At daily and weekly temporal resolutions, lines represent the linear regression model for top and bottom leaves, respectively. Statistical significance of the adjusted r-square are denoted by asterisks (* p-value $<0.05$; $* *$ p-value $<0.01$; $* * * \mathrm{p}$ value $<0.001$ ). Daily and weekly APAR values were obtained by summing hourly measurements and then diving by number of hours in a day and number of days in a week, respectively. 


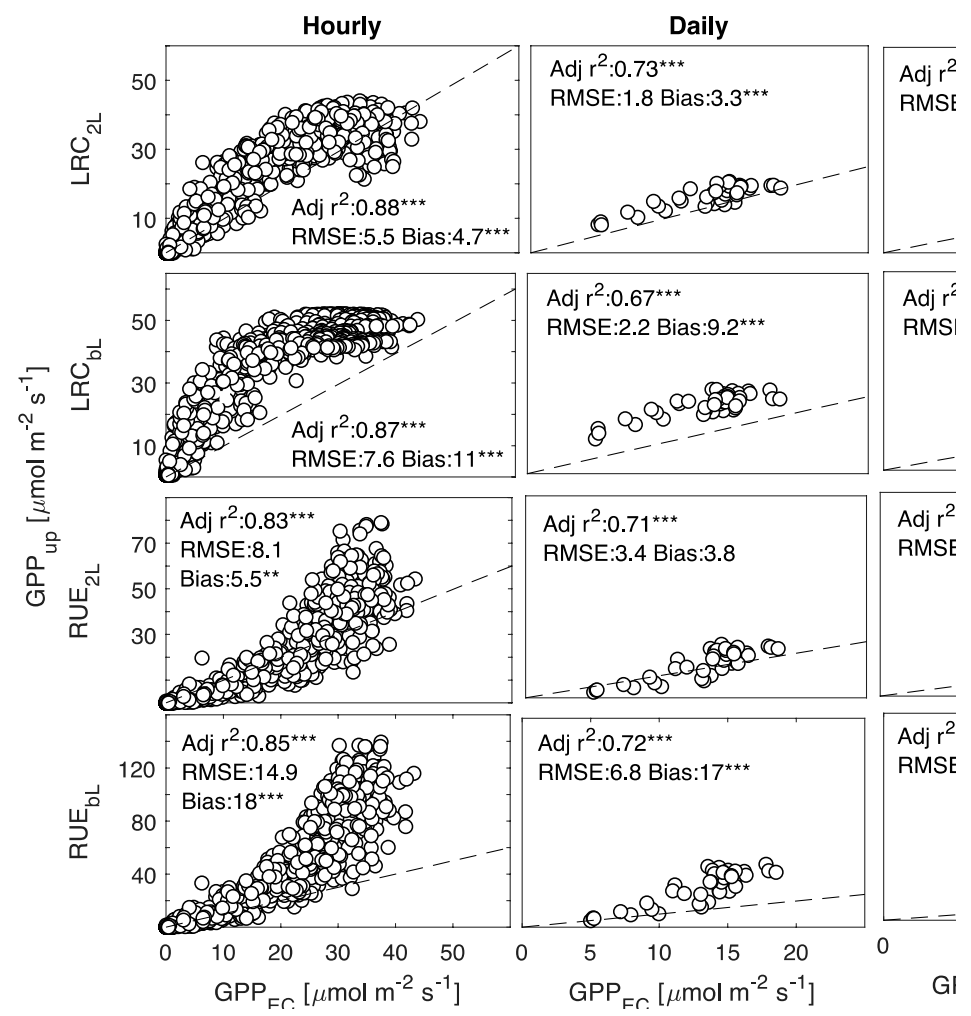

Fig 6. Upscaled barley leaf-level photosynthesis ( $\mathrm{GPP}_{\mathrm{up}}$ ) plotted against eddy covariance (EC) gross primary production (GPPEC) estimates. Four different leaf-to-canopy photosynthesis upscaling schemes were used: top/bottom-leaf Light Response Curve ( $\mathrm{LRC}_{\mathrm{tb}}$ ), one-leaf Light Response Curve (LRC $1 \mathrm{~L}$ ), top/bottom-leaf Radiation Use Efficiency (RUE $\mathrm{tb}_{\mathrm{tb}}$ ), one-leaf Radiation Use Efficiency $\left(\mathrm{RUE}_{1 \mathrm{~L}}\right)$. Comparisons are presented at daily and weekly temporal resolutions. The adjusted $r^{2}$ (Adj $r^{2}$ ), the root mean square error (RMSE) and the bias are reported, statistical significance of $\mathrm{r}^{2}$ and of bias are denoted by asterisks ( $*$ p-value $<0.05$; ** p-value $<0.01 ; * * *$ p-value $<0.001)$. 


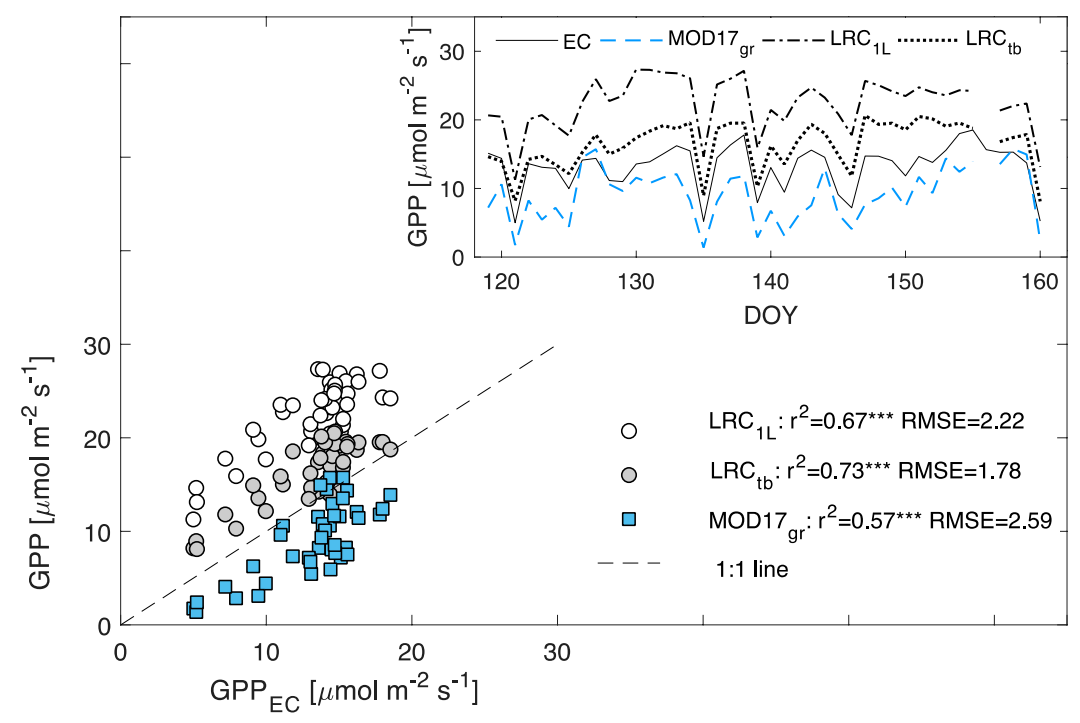

Fig 7. Barley upscaled gross primary production $\left(\mathrm{GPP}_{\mathrm{up}}\right)$ plotted against eddy covariance (EC) gross primary production $\left(\mathrm{GPP}_{\mathrm{EC}}\right)$ estimates. Three upscaling approaches are compared: the two best performing leaf-to-canopy photosynthesis upscaling schemes (i.e., the top/bottom-leaf light response curve $\left(\mathrm{LRC}_{\mathrm{tb}}\right)$ and the one-leaf light response curve $\left(\mathrm{LRC}_{1 \mathrm{~L}}\right)$ ) and a remote sensing approach based on a ground adaptation of MODIS gross primary productivity algorithm (MOD17gr) and proximal sensing daily NDVI time series obtained from UniSpecDC (PP Systems) measurements. Inset: Daily GPP $\mathrm{up}_{\text {and }}$ GPP $\mathrm{EC}_{\mathrm{EC}}$ during the measurement period. 
Table 1. Four different leaf-to-canopy photosynthesis upscaling schemes considered in this study. Absorbed PAR for top, bottom and entire canopies are obtained from PAR profile measurements. Required inputs and datasets used for model calibration are listed.

\begin{tabular}{|c|c|c|c|}
\hline Scheme & Formulation & Inputs & $\begin{array}{l}\text { Data used for model calibration } \\
\text { (References) }\end{array}$ \\
\hline $\begin{array}{l}\text { top/bottom-leaf light } \\
\text { response curve } \\
\text { (LRC } \text { tb }^{\text {) }}\end{array}$ & $\begin{array}{l}A_{\text {total }}=A_{\text {top }}+A_{\text {bottom }} \text {, where } \\
A_{\text {top }}=\left(\operatorname{Amax}_{\text {top }}+\operatorname{Rd}_{\text {top }}\right)\left(1-\exp \left(\frac{-\phi_{\text {top }} A_{\text {PAR }} \text { top }}{\text { Amax }_{\text {top }}+\operatorname{Rd}_{\text {top }}}\right)\right)-\operatorname{Rd}_{\text {top }} \\
A_{\text {bottom }}=\left(\operatorname{Amax}_{\text {bottom }}+\operatorname{Rd}_{\text {bottom }}\right)\left(1-\exp \left(\frac{-\phi_{\text {bottom }} A_{\text {PAR }} A_{\text {bottom }}}{\text { max }_{\text {bottom }}+\operatorname{Rd}_{\text {bottom }}}\right)\right)-\operatorname{Rd}_{\text {bottom }}\end{array}$ & $\begin{array}{l}\operatorname{Amax}_{\text {top }}, \mathrm{Amax}_{\text {bottom }} \\
\phi_{\text {top }}, \phi_{\text {bottom }} \\
\mathrm{Rd}_{\text {top }}, \mathrm{Rd}_{\text {bottom }} \\
\mathrm{APAR}_{\text {top }}, \mathrm{APAR}_{\text {bottom }}\end{array}$ & $\begin{array}{l}\text { Physiological variables are derived from } \\
\text { top and bottom leaves Li-6400 LRC } \\
\text { measurements. }\end{array}$ \\
\hline $\begin{array}{l}\text { one-leaf light } \\
\text { response curve } \\
\left(\mathrm{LRC}_{1 \mathrm{~L}}\right)\end{array}$ & $A_{\text {total }}=(\overline{\mathrm{Amax}}+\overline{\mathrm{Rd}})\left(1-\exp \left(\frac{-\bar{\phi} \mathrm{APAR}}{\overline{\mathrm{Amax}}+\overline{\mathrm{Rd}}}\right)\right)-\overline{\mathrm{Rd}}$ & $\begin{array}{l}\overline{\operatorname{Amax}}, \bar{\phi}, \overline{\mathrm{Rd}} \\
\mathrm{APAR}\end{array}$ & $\begin{array}{l}\text { Average physiological variables derived } \\
\text { from leaf-level Li-6400 LRC } \\
\text { measurements. }\end{array}$ \\
\hline $\begin{array}{l}\text { top/bottom-leaf } \\
\text { radiation use } \\
\text { efficiency }\left(R_{U} E_{t b}\right)\end{array}$ & 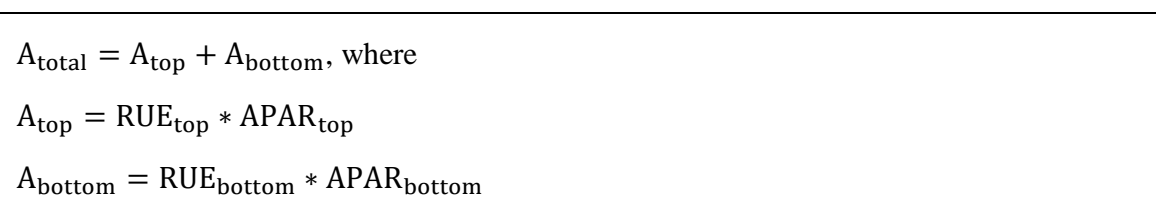 & $\begin{array}{l}\mathrm{RUE}_{\text {top }}, \mathrm{RUE}_{\text {bottom }} \\
\mathrm{APAR}_{\text {top }}, \mathrm{APAR}_{\text {bottom }}\end{array}$ & $\begin{array}{l}\text { The Radiation Use Efficiency (RUE) } \\
\text { coefficients are obtained as the ratio of } \\
\text { photosynthesis (measured at leaf-level and } \\
\text { upscaled based on LAI) to absorbed PAR } \\
\text { for top and bottom canopy separately. }\end{array}$ \\
\hline $\begin{array}{l}\text { one-leaf radiation use } \\
\text { efficiency (RUE1L) }\end{array}$ & $\mathrm{A}_{\text {total }}=\overline{\mathrm{RUE}} * \mathrm{APAR}$ & $\overline{\mathrm{RUE}}, \mathrm{APAR}$ & $\begin{array}{l}\text { Average Radiation Use Efficiency (RUE) } \\
\text { coefficient obtained as the ratio of } \\
\text { photosynthesis (measured at leaf-level and } \\
\text { upscaled based on LAI) to absorbed PAR } \\
\text { by entire canopy. }\end{array}$ \\
\hline
\end{tabular}

LRC is Light Response Curve; PAR is Photosynthetically Active Radiation; APAR is Absorbed Photosynthetically Active Radiation; RUE is Radiation Use Efficiency.

Subscripts tb and $1 \mathrm{~L}$ indicate top/bottom and one-leaf upscaling schemes, respectively. Amax is maximum photosynthetic capacity; Rd is dark respiration; and $\Phi$ is quantum yield; overbar denotes averages. 
Table 2. Coefficients used for the four photosynthesis upscaling schemes applied for barley and rape seed crop types expressed in units of $\mu \mathrm{mol} \mathrm{m} \mathrm{m}^{-2} \mathrm{~s}^{-1}$. The upscaling schemes are given in Table 1.

\begin{tabular}{|c|c|c|}
\hline \multirow{2}{*}{ Model } & \multicolumn{2}{|c|}{ Coefficients } \\
\hline & Barley & Rape seed \\
\hline \multirow[t]{2}{*}{$\mathrm{LRC}_{\mathrm{tb}}$} & $\begin{array}{c}\phi_{\text {top }}=0.058 ; \text { Amax }_{\text {top }}=13.07 ; R d_{\text {top }} \\
=1.07\end{array}$ & $\begin{array}{c}\phi_{t o p}=0.083 ; A_{\max } \text { top }=20.75 ; R d_{t o p} \\
=2.60\end{array}$ \\
\hline & $\begin{aligned} \phi_{\text {bottom }}=0.074 ; \text { Amax }_{\text {bottom }} & \\
& =6.93 ; d_{\text {bottom }}=0.74\end{aligned}$ & $\begin{aligned} \phi_{\text {bottom }}=0.103 ; \text { Amax }_{\text {bottom }} & \\
& =11.08 ; \text { Rd }_{\text {bottom }}=1.52\end{aligned}$ \\
\hline $\mathrm{LRC}_{1 \mathrm{~L}}$ & $\bar{\phi}=0.066 ; \overline{A \max }=10 ; \overline{R d}=0.9$ & $\bar{\phi}=0.093 ; \overline{A \max }=15.92 ; \overline{R d}=2.06$ \\
\hline \multirow{2}{*}{$\mathrm{RUE}_{\mathrm{tb}}$} & $R U E_{\text {top }}=0.022$ & $R U E_{\text {top }}=0.037$ \\
\hline & $R U E_{\text {bottom }}=0.012$ & $R U E_{\text {bottom }}=0.017$ \\
\hline $\mathrm{RUE}_{1 \mathrm{~L}}$ & $\overline{R U E}=0.017$ & $\overline{R U E}=0.022$ \\
\hline
\end{tabular}



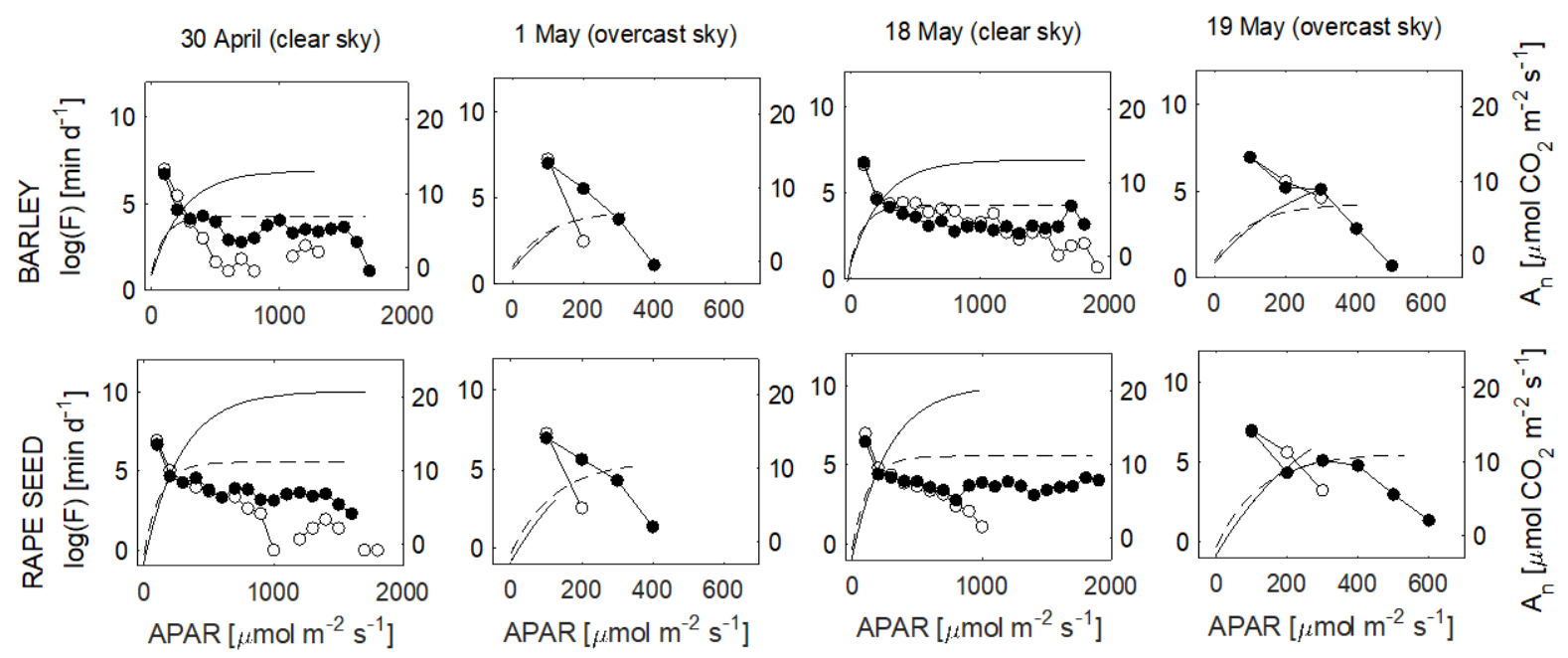

Fig S1. Frequency distribution of the total PAR absorbed by top (unfilled circles) and bottom (filled circles) canopy during subsequent clear and overcast days for barley (top row) and rape seed (bottom row). Each point represents the natural log of number of minutes per day for which absorbed PAR was within a given class of PAR. The leaf-level net photosynthesis light response curves $\left(A_{n}\right)$ as estimated using Eq. 1 for top (solid line) and bottom (dashed line) leaves are also shown for the same days. The measured photosynthesis light response curve parameters (Amax, $\phi$, Rd) for top and bottom leaves were used in combination with the measured APAR at the respective leaf height. 
Table S1. Means ( \pm standard deviations) of top and bottom barley and rape seed leaf traits. Statistics for top and bottom leaf mean difference: degree of freedom (df), $p$-values and t-values are given from a two-tailed test. *, $\mathrm{p} \leqq 0.05 ;{ }^{* *}, \mathrm{p} \leqq 0.01 ; * * *, \mathrm{p} \leqq 0.001$; NS, not significant.

\begin{tabular}{|c|c|c|c|c|c|c|}
\hline Variables & Crop & Тор & Bottom & $\begin{array}{l}\mathrm{t}- \\
\text { value }\end{array}$ & $\mathrm{df}$ & $\begin{array}{l}\mathrm{p}- \\
\text { value }\end{array}$ \\
\hline \multirow{2}{*}{$\begin{array}{c}\text { Amax } \\
{\left[\mu \mathrm{mol} \mathrm{m}^{-2} \mathrm{~s}^{-1}\right]}\end{array}$} & barley & $13.1( \pm 6.7)$ & $6.9( \pm 2.6)$ & 3.7 & 32 & $* * *$ \\
\hline & $\begin{array}{l}\text { rape } \\
\text { seed }\end{array}$ & $20.8( \pm 5.8)$ & $11.1( \pm 6.7)$ & 3.7 & 25 & $* *$ \\
\hline \multirow[b]{2}{*}{$\phi$} & barley & $0.058( \pm 0.032)$ & $0.074( \pm 0.025)$ & 2.069 & 32 & * \\
\hline & $\begin{array}{l}\text { rape } \\
\text { seed }\end{array}$ & $0.083( \pm 0.019)$ & $0.103( \pm 0.027)$ & 2.17 & 25 & $*$ \\
\hline \multirow{2}{*}{ 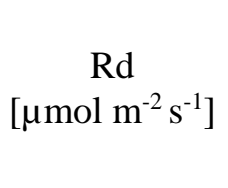 } & barley & $1.1( \pm 0.5)$ & $0.7( \pm 0.3)$ & 2.1 & 30 & $*$ \\
\hline & $\begin{array}{l}\text { rape } \\
\text { seed }\end{array}$ & $2.6( \pm 1.4)$ & $1.5( \pm 0.7)$ & 2.9 & 25 & $* *$ \\
\hline \multirow{2}{*}{$\begin{array}{c}\mathrm{N} \\
{\left[\mathrm{g} \mathrm{m}^{-2}\right]}\end{array}$} & barley & $2.0( \pm 0.2)$ & $1.0( \pm 0.2)$ & 14.2 & 41 & $* * *$ \\
\hline & $\begin{array}{l}\text { rape } \\
\text { seed }\end{array}$ & $3.3( \pm 1.0)$ & $2.3( \pm 0.5)$ & 3.0 & 25 & $* *$ \\
\hline \multirow{2}{*}{$\begin{array}{c}\mathrm{C} \\
{\left[\mathrm{g} \mathrm{m}^{-2}\right]}\end{array}$} & barley & $23.0( \pm 2.4)$ & $18.3( \pm 2.3)$ & 6.2 & 41 & $* * *$ \\
\hline & $\begin{array}{l}\text { rape } \\
\text { seed }\end{array}$ & $32.8( \pm 9.5)$ & $29.2( \pm 7.5)$ & 1.1 & 25 & NS \\
\hline \multirow{2}{*}{$\begin{array}{c}\mathrm{Chl} \\
{\left[\mathrm{mg} \mathrm{m}^{-2}\right]}\end{array}$} & barley & $507.6( \pm 59.6)$ & $406.2( \pm 60.4)$ & 5.2 & 36 & $* * *$ \\
\hline & $\begin{array}{l}\text { rape } \\
\text { seed }\end{array}$ & $518.6( \pm 34.9)$ & $511.3( \pm 41.6)$ & 0.4 & 20 & NS \\
\hline \multirow{2}{*}{$\begin{array}{l}\text { LMA } \\
{\left[\mathrm{g} \mathrm{m}^{-2}\right]}\end{array}$} & barley & $51.9( \pm 5.8)$ & $42.7( \pm 5.2)$ & 5.4 & 41 & $* * *$ \\
\hline & $\begin{array}{l}\text { rape } \\
\text { seed }\end{array}$ & $77.1( \pm 22.6)$ & $70.9( \pm 18.1)$ & 0.8 & 25 & NS \\
\hline
\end{tabular}

